C2016, Elsevier. Licensed under the Creative Commons Attribution-NonCommercialNoDerivatives 4.0 International http://creativecommons.org/about/downloads (c) (†) $\odot$ 


\title{
THERMAL ENERGY STORAGE USING METAL-ORGANIC FRAMEWORK MATERIALS
}

\section{Ahmed Elsayed ${ }^{\text {a,b,c }}$, Eman Elsayed ${ }^{a}$, Raya AL-Dadah ${ }^{a}$, Saad Mahmoud ${ }^{a}$, Amr Elshaer ${ }^{d}$, Waseem Kaialy}

\author{
${ }^{\text {a }}$ School of Mechanical Engineering, University of Birmingham, Birmingham, B15 2TT, UK. \\ ${ }^{\mathrm{b}}$ Institute for Advanced Manufacturing and Engineering (AME), School of Engineering and computing, Coventry \\ University, Coventry, CV6 5LZ, UK. \\ ${ }^{\mathrm{c}}$ Mechanical Engineering Department, Alexandria University, Alexandria, Egypt. \\ ${ }^{\mathrm{d}}$ Kingston University London, School of Pharmacy and Chemistry, London, UK. \\ ${ }^{\mathrm{e}}$ School of Pharmacy, University of Wolverhampton, Wolverhampton, WV1 1LY, UK. \\ * Corresponding author. Email: ahmed.elsayed.1981@ gmail.com; Tel. 07916774790
}

\begin{abstract}
Metal-organic framework (MOF) materials are new adsorbent materials that have high surface area and pore volume and hence high adsorption uptake. The previous exceptional properties make this class of materials to have a great potential in many applications like cooling, gas separation and energy storage. However, there is very limited information on the performance of metal-organic framework materials in energy storage applications and their performance compared to conventional adsorbents. This paper aims to present an experimental characterization of CPO-27(Ni) MOF material for water adsorption and to investigate its viability for energy storage. CPO-27(Ni) (known as MOF$74(\mathrm{Ni})$ ), which is a MOF material that has high water adsorption capabilities of $0.47 \mathrm{~g}_{\mathrm{H} 2 \mathrm{O}} \cdot \mathrm{gads}^{-1}$ and hydrothermally stable and can be supplied in large quantities. Firstly, the material water adsorption isotherms were predicated using Materials Studio software via the material structure information and then compared to the experimentally measured isotherms. The experimentally measured isotherms and kinetics were used to model a double bed adsorption system for energy storage application using Simulink-Matlab software coupled with Nist RefProp thermophysical routines. Finally, the performance of CPO-27(Ni) was then compared with silica gel. The CPO-27(Ni) was found to outperform silica gel at long half cycle time (more than 30 minutes) at low evaporating temperature making it suitable for energy storage applications. The energy stored in the condenser and the adsorption bed was found to be dependent mostly on the regeneration and the cooling temperatures. The potential of the energy recovered from the adsorption bed can be double the one recovered from the condenser. Also, the energy recovery during condensation and adsorption was found to be independent of the reactor conductance except at small conductance ratio. Finally, the adsorption unit cooling water flow strategy was found to affect the amount of the energy recovered as recirculating the cooling water through the adsorption bed and then condenser was found to decrease the recovered energy from condenser by $4 \%$.
\end{abstract}

Keywords Adsorption, energy storage, metal organic frameworks, characterization. 


\section{Introduction}

Thermal energy storage (TES) is considered as an important technology to utilize the renewable energy and waste heat offering a great potential for reducing the $\mathrm{CO}_{2}$ emissions and cost reduction. The most common thermal energy storage methods are the sensible heat storage (water tanks) and latent heat storage (ice or phase change materials). Sensible heat storage systems are based on the heat exchanging process between energy storage materials such as oxide ceramics [1], concrete [2] and heat exchange fluid such as water [1], molten salts [3] or oil [4, 5]. To reduce the volume of sensible thermal storage system and increase the thermal storage efficiency, a high thermal storage capacity (sensible heat capacity) is required. Latent heat storage systems depends on the heat charging or discharging during phase change process of the phase change materials (PCM) such as $\left[\mathrm{CaCl}_{2} \cdot 6 \mathrm{H}_{2} \mathrm{O}\right.$, Paraffin wax (P116) and $\mathrm{Na}_{2} \mathrm{SO}_{4} \cdot 10 \mathrm{H}_{2} \mathrm{O}$ ] [6]. During the charging the PCM store the energy, while during the discharging, the PCM crystallizes delivering the stored energy. Energy storage have been integrated with PCM and compressed air [7], high temperature PCM /solar collector, chilled water/low temperature PCM ground water heat exchanger [8]. The efficiency of any latent heat storage system was found to depend on the selection of PCM (depending mainly on the charging temperature) and geometric design (cylindrical and rectangular configurations) of the storage system $[9,10,11]$. A large number of researches reviewed the recent work carried out in the Thermal Energy Storage (TES) technologies and systems [12], phase change material (PCM), design considerations and performance enhancement techniques [13], performance enhancement in latent heat thermal storage system [14], materials heat transfer and phase change problem formulation for latent heat TES system [15] and TES for residential application [16]. However, the sensible and latent heat storage systems were found to have a low storage density and long term and long-time storage and unacceptable energy loss [17]. Recently, the sorption phenomenon was applied for the same purpose as the sensible and latent heat in heat storage systems. The adsorption heat storage system has numerous advantages such as the high energy storage density (from the adsorption bed and the condenser), the long-term heat storage capability and the flexible working modes. Adsorption thermal energy storage is considered to be a promising technology that can provide an excellent solution for long-term thermal energy storage in a more compact and efficient way. A heat source promotes the dissociation (endothermic process) of a working pair, whose substances can be stored separately. When they come into contact again, heat is released (exothermic process). Therefore, the energy can then be stored with virtually no loss because the heat is not stored in a sensible or latent form but rather as potential energy, as long as the substances are kept separate [18]. The storage density could be increased by improving the mass flow and the heat conduction of the adsorbent bulk [19]. 
The main aim of the research in the various adsorption applications is to develop a compact and efficient adsorption system. Those objectives could be realized by using properly designed heat exchangers [20], cycle operating strategies (mass recovery, heat recovery, cascading...etc) [21] and developing adsorbent materials with high cyclic uptake [22]. The selection of adsorbent material is considered to be a key factor in the design and manufacturing of any adsorption system [22-27]. All the reported energy storage adsorption projects have used conventional adsorbents such as silica gel and zeolite [25]. Metal-Organic Framework (MOF) materials are new porous materials with high surface area, pore size and volume, and tunable pore geometry thus providing higher adsorption capacity compared to silica gel and zeolite. Very limited information is available on the performance of metal-organic frameworks material in energy storage applications and their performance compared to conventional adsorbents which was the motivation for the authors to hold such comparison. Metal-organic framework materials are considered to be promising alternative adsorbents for the conventional zeolites and silica gel. MOFs have been recently applied for a wide range of applications including gas storage (methane storage [26] and hydrogen storage [27]). Another adsorption application, sorption thermal energy storage has been proposed for different applications including air heating systems (buildings or radiators) or floor heating systems [28]. Different materials and composites have been investigated for the sorption energy storage including silica gel [28], silica gel / calcium chloride composites [29]. This application exhibits high energy storage density compared to latent and sensible energy storage where such systems should be easy to handle, environmentally friendly, relatively cheap, thermally stable and with a high sorbate uptake. However, appropriate heat and mass transfer properties must be applied to ensure the designed output power [30, 31].

Different demonstrations of physical adsorption projects were carried out to investigate the capability of solid-gas adsorption for energy storage application such as Monosorp and Modestor [28, 30, 18, 32, 33] using conventional adsorbents. In which, the importance of achieving a good contact between the adsorbent and the heat exchanger has been mentioned. The particles sizes that were usually used were smaller than $2 \mathrm{~mm}$, preferably between $0.2 \mathrm{~mm}$ and $0.6 \mathrm{~mm}$ for zeolites, silica gel and their composite-based materials depending on the bed wall thickness. It has been reported that using adsorbents in the form of pellets showed bad contact between the heat exchanger walls and the adsorbent [34]. Finck et al. [35] used zeolite 5A/water pair for $3 \mathrm{kWh}$ thermochemical heat storage modules for space heating application. Forty one $\mathrm{kg}_{\mathrm{s}}$ of zeolite in the form of spheres (diameter 2$3 \mathrm{~mm}$ ) were used in a packed bed in the form of finned heat exchanger, placed in a cylindrical vessel of stainless steel, 8 heat exchanger blocks with sizes of 1000x300x33mm (height $\mathrm{x}$ width $\mathrm{x}$ depth). The water temperature in the adsorption bed was raised from $20^{\circ} \mathrm{C}$ to $25^{\circ} \mathrm{C}$ during the release of the energy stored by adsorption. A temperature difference of $20 \mathrm{~K}$ between the condenser and the adsorption bed temperature was found to reduce the heat released by adsorption from $3.5 \mathrm{kWh}$ to 2.5 
$\mathrm{kWh}$ (30 \% less energy released). Decreasing the evaporation or increasing the adsorption temperature was found to decrease the energy stored by $16 \%$ per $5^{\circ} \mathrm{C}$ and $20 \%$ per $10^{\circ} \mathrm{C}$ temperature change, respectively in open adsorption systems using calcium chloride as adsorbent with energy density of $1 \mathrm{~kJ} / \mathrm{g}$ (277 Wh/kg) [36]. Janchen, H. Stach [37] tested different types of zeolites where the energy density was found to be in the range of $160 \mathrm{Wh} / \mathrm{kg}$. Marie et al. [38] developed a fluid dynamic model for the charge/discharge process including the four cyclic processes of charging / discharging conditions with a half cycle time of 4 hours. Li et al. [39] studied an energy storage system based on SAPO-34 as the adsorbent material; an energy density of $230 \mathrm{Wh} / \mathrm{kg}$ was reported. Another adsorption system using water as the adsorbate and MIL-101(MOF material) as the adsorbent has been reported by Henninger et al. [40]. Additionally, they investigated different structured materials including classical zeolite, metal-organic framework (HKUST-1 or Cu-BTC) and aluminophosphates (AIPO-18). Henninger and co-authors showed that the water adsorption capacities of MIL-100 and MIL-101 types surpass those of any conventional adsorbent material. However, these exceptional compounds are synthesized only on a lab scale and are difficult to be mass produced which is not the case with CPO-27(Ni) as it is mass produced by Johnson Matthey, UK. As mentioned before, the reviewed research has limited information on the performance of metal-organic framework materials in energy storage applications and their performance compared to conventional adsorbents. Based on the authors knowledge the working pair of (CPO-27(Ni)/water) has not been investigated for energy storage application in any previous published articles. The current research focus on improving the energy density based on operating conditions and cooling water flow strategies. The CPO-27(Ni) was found to outperform silica gel and even other MOF materials such as MIL-100 and MIL-101 at low evaporation temperatures $\left(<7^{\circ} \mathrm{C}\right)$. At higher evaporation temperatures, the material exhibited an energy density of $170 \mathrm{Wh} / \mathrm{kg}$ where long cycle time of more than 30 minutes is recommended in energy storage applications. Also, it found that the potential of energy recovered from the adsorption bed is double that recovered from the condenser. Finally, a comparison between two cooling water flow strategies concluded that recirculating the cooling water through the adsorption bed and then the condenser decreased the recovered energy from the condenser by $4 \%$.

\section{CPO-27(Ni) characterisation}

For adsorption based energy storage, the system modelling and the characteristics of $\mathrm{CPO}-27(\mathrm{Ni})$ should be determined. These characteristics include the material structure, the water adsorption isotherm and kinetics, the hydrothermal stability and the heat of adsorption. These are described in the following sections.

\subsection{Structure analysis}

The powder X-ray diffraction (PXRD) patterns of the CPO-27(Ni) powder was measured using Siemens DIFFRACplus 5000 powder diffractometer with $\mathrm{Cu} \mathrm{K} \alpha$ radiation (1.54056 ̊). Each sample 
was scanned from 5 to $80^{\circ} 2 \theta$, with a step size of $0.02^{\circ}$ at $2 \mathrm{step} / \mathrm{sec}$. The sample was spun at $30 \mathrm{rpm}$. The sharp peaks of the CPO-27(Ni) pattern highlight its high crystallinity. Materials studio software has been used to simulate the XRD and adsorption isotherm based on the crystal structure of the material. Fig. 1a shows the crystal structure of CPO-27(Ni), organic and inorganic Secondary Building Units (SBUs). The material has a honeycomb-like network with 1D pore structure. Fig. 1b shows the measured XRD pattern compared to that predicted from the Materials Studio software where good agreement could be observed.

The particle size of CPO-27(Ni) was measured through a vibrating sieving facility, it was found to be between 125 micron to 355 micron. Laser diffraction technique was used to define the particle size distribution as shown in Fig. 1c showing that bimodal size distribution could be divided into two populations which suggests that after the mechanical sieving, the CPO-27(Ni) sample still contained a portion of fine particles. The sample showed a VMD (D10\% - D90\%) of $205.0 \pm 62.2 \mu \mathrm{m}(1.1 \pm 0.0$ $\mu \mathrm{m}-633.8 \pm 207.7 \mu \mathrm{m})$ that fell between the nominal sieve size ranges, i.e., $125-355 \mu \mathrm{m}$, suggesting that the applied sieving process was satisfactorily efficient.

Using Pelsorb test facility, Table 1 shows the specification of surface area using Brunauer-EmmettTeller (BET) method. Micropore (MP) method was used to calculate the pore size distribution. Each sample of about 50-100 mg was degassed under vacuum (about $5 \mu \mathrm{m} \mathrm{Hg}$ ) and at $\mathrm{T}=353 \mathrm{~K}$ for 2 hours. It is observed from Fig. 2 that the peak volume distribution appears to be less than $1 \mathrm{~nm}$ which means the material has a micropore structure.

\subsection{Water adsorption isotherms}

Adsorption isotherms and kinetics are required to predict the water uptake at various operating conditions. The water adsorption characteristics were measured using a Dynamic Vapour Adsorption analyser (DVS) (Advantage DVS, Surface Measurement Systems, UK). Fig. 3a shows the adsorption isotherms of $\mathrm{CPO}-27(\mathrm{Ni})$ and silica gel-RD at $25^{\circ} \mathrm{C}$, it is observed that $\mathrm{CPO}-27(\mathrm{Ni})$ has a higher uptake especially at low pressure ratio compared to silica gel. The steep profile of CPO-27(Ni) is preferable especially for adsorption systems that work at low ambient temperatures. Additionally, the water adsorption isotherm was predicted through Materials studio software showing once again good agreement between the experimentally measured and the simulated isotherms. From the figure, CPO$27(\mathrm{Ni})$ exhibited a type I adsorption isotherm reaching $81 \%$ of its capacity at a very low relative pressure and then a plateau reaching its maximum uptake of $0.47 \mathrm{~g}_{\mathrm{H} 2 \mathrm{O}} \cdot \mathrm{gads}^{-1}$ at a relative pressure of 0.9. This performance is due to the presence of unsaturated metal centres (UMCs) existing in this MOF structures. UMCs are metal binding sites formed after the removal of axial ligands from metal atoms (Fig. 1a) attracting water molecules and offering extra binding sites to the guest molecules, especially at low pressure values. On the other hand, the strong interaction between the water molecules and these sites requires a higher desorption temperature. Fig. 3b shows the effect of the isotherm temperature on the uptake capacity of the material. The material was found to possess a 
stable performance and exhibit the same water uptake under the investigated temperatures $\left(25^{\circ} \mathrm{C}\right.$, $35^{\circ} \mathrm{C}$ and $\left.55^{\circ} \mathrm{C}\right)$.

In order to investigate the hydrothermal stability of the material, it was exposed to five successive water adsorption/desorption cycles at $55^{\circ} \mathrm{C}$ using DVS test facility as shown in Fig. 4. It is clear that the material exhibits a stable performance over the cycles. This highlights the high thermal stability of the material. Such performance is advantageous over other metal-organic framework materials such as MIL-100 and HKUST-1 where the uptake was found to decrease after the first cycle.

The experimental data has been fitted to adsorption potential using Dubinin- Astakhov equation as shown in Fig. 5; such fitting between uptake (x) and adsorption potential (A) (as shown in equation 1) is required for the performance modelling of the adsorption heat storage system.

$x=0.462248 * \exp \left(-\left[\frac{\mathrm{A}}{10019.2}\right]^{4}\right)$

\subsection{Adsorption kinetics}

The adsorption kinetics or the rate of adsorption was represented in Fig. 6 showing the water fractional uptake of CPO-27(Ni) versus time at two different temperatures $\left(25^{\circ} \mathrm{C}\right.$ and $\left.55^{\circ} \mathrm{C}\right)$ and two relative pressures $(0.05$ and 0.1$)$. This data was fitted in the form of equation 2 to predict the adsorption rate as:

$$
\frac{d x}{d t}=k_{0} \cdot \exp \left[-\frac{E_{a}}{R T}\right] \cdot\left(x_{e q}-x\right)
$$

Where $\mathrm{k}_{0}$ was found to be $5.108[1 / \mathrm{s}]$ and $\mathrm{E}_{\mathrm{a}}$ is $25125.93[\mathrm{~J} / \mathrm{mol}]$, the highest deviation between the experimental data for both materials and the proposed model did not exceed $7 \%$. It could be observed that the higher the temperature, the shorter the time required to reach full capacity of the material at certain condition. Also, lower partial pressure requires longer characteristic time to reach the full capacity. i.e., a smaller adsorption rate constant and a slower adsorption process.

\subsection{Heat of adsorption}

The measured isotherms were used to plot the pressure, temperature, concentration diagram (P-T-X), and the heat of adsorption was calculated using equation 3 as:

$$
\Delta H_{a d s}=-R_{\text {water }} \frac{\partial \ln (P)}{\partial\left(\frac{1}{T}\right)}
$$

The heat of adsorption was calculated to be $2626 \mathrm{~kJ} / \mathrm{kg}_{\text {ads }}$. 
The predicted isotherms and kinetics of the MOF material was incorporated in a SIMULINK model developed by Elsayed et al. [41] to compare the performance of CPO-27(Ni) and silica gel-RD under transient operation. The adsorption/desorption rate has been modelled using the linear driving force theory equation 4. Equations 5 to 13 describes the thermodynamic model of the adsorption / desorption in the adsorption bed, the mass balance equation of the evaporator, the heat balance equation for the evaporator, the heat balance equation of the condenser and finally the heat balance equation for the adsorption bed.

$$
\frac{d x}{d t}=\frac{F_{p} D_{s o}}{R_{p}^{2}} \cdot \exp \left[-\frac{E_{a}}{R T}\right] \cdot\left(x_{e q}-x\right)
$$

The overall mass balance recirculated in the chiller:

$$
\frac{d M_{r e f, e v a p}}{d t}=-M_{a d s} \frac{d x_{d e s}}{d t}-M_{a d s} \frac{d x_{a d s}}{d t}
$$

The adsorption/desorption temperature was predicted using the energy balance as:

$$
\left(M_{a d s}\left(C_{a d s}+x C_{r e f, v}\right)+M_{c u, a d s} C_{c u, a d s}+M_{a l, a d s} C_{a l, a d s}\right) \frac{d T_{a d s}}{d t}=M_{a d s} H_{a d s} \frac{d x}{d t}+m_{w}^{\bullet} C_{w}\left(T_{w, i n}-T_{w, o u t}\right)
$$

The outlet heat source/ cooling medium are calculated from the logarithmic mean temperature:

$$
T_{w, o u t}=T_{a d s}+\left(T_{w, i n}-T_{a d s}\right) \exp \left(-\frac{U_{a d s} A_{a d s}}{m_{w}^{\bullet} C_{w}}\right)
$$

the evaporation temperature was calculated as (Akahira et al. [42]):

$$
\begin{aligned}
& \left(M_{\text {ref,evap }} C_{r e f, l}+M_{\text {cu, evap }} C_{\text {cu,evap }}\right) \frac{d T_{\text {evap }}}{d t}=-\left(M_{a d s} \frac{d x_{a d s}}{d t}\right) h_{f g}-M_{a d s} C_{r e f, l} T_{\text {cond }} \frac{d x_{\text {des }}}{d t} \\
& +m_{\text {chill }}^{\cdot} C_{w}\left(T_{\text {chill, in }}-T_{\text {chill,out }}\right)-M_{a d s} C_{r e f, v} T_{\text {evap }} \frac{d x_{a d s}}{d t}
\end{aligned}
$$

The chilled water outlet temperature was calculated as:

$$
T_{\text {chill,out }}=T_{\text {evap }}+\left(T_{\text {chill, in }}-T_{\text {evap }}\right) \exp \left(-\frac{U_{\text {evap }} A_{\text {evap }}}{m_{\text {chill }}^{\bullet} C_{w}}\right)
$$

The condenser energy balance (Akahira et al. [42]):

$$
\begin{aligned}
& \left(M_{c u, c o n d} C_{c u, c o n d}\right) \frac{d T_{\text {cond }}}{d t}=-\left(M_{a d s} \frac{d x_{d e s}}{d t}\right) h_{f g}+M_{a d s} C_{r e f, l} T_{\text {cond }} \frac{d x_{d e s}}{d t} \\
& +m_{\text {cooling }}^{\cdot} C_{w}\left(T_{\text {cooling,in }}-T_{\text {cooling,out }}\right)-M_{a d s} C_{r e f, v} T_{\text {cond }} \frac{d x_{d e s}}{d t}
\end{aligned}
$$

The cooling water outlet temperature was calculated as:

$$
T_{\text {cooling,out }}=T_{\text {cond }}+\left(T_{\text {cooling,in }}-T_{\text {cond }}\right) \exp \left(-\frac{U_{\text {cond }} A_{\text {cond }}}{m_{\text {cooling }}^{\bullet} C_{w}}\right)
$$

The cooling capacity and COP were calculated as: 
$Q_{\text {evap }}=\frac{m_{\text {chill }}^{\cdot} C_{w} \int_{0}^{t_{\text {ocde }}}\left(T_{\text {chill, in }}-T_{\text {chill,out }}\right) d t}{\text { tcycle }}$

$Q_{\text {hot }}=\frac{m_{h o t}^{\cdot} C_{w} \int_{0}^{t_{\text {cole }}}\left(T_{\text {hot,in }}-T_{\text {hot,out }}\right) d t}{\text { tcycle }}$

\section{$7 \quad$ Results and discussion}

The layout arrangement of the Simulink model used to solve the system of the previous ordinary differential equations representing the transient thermal analysis of adsorption system is shown in Fig. 7a. The model was validated through the comparison with the experimental data previously published by Saha et al. [43] as shown in Fig. 7b. From the figure, it can be seen that the model successfully predicated the reported data with a deviation not exceeding $5 \%$. After the validation, the same model was used to predict both the adsorption and condensation energies that could be usefully stored in case of CPO-27(Ni) and silica gel in energy storage application. The operating conditions for the energy storage system are summarized in Table 2 where the heat recovered from the condenser and adsorption bed are the main targets.

The energy distribution for both cooling and heating which could be recovered from the evaporator, the condenser and the adsorption bed for both materials (silica gel and CPO-27(Ni)) at different half cycle times is represented in Fig. 8. It is evident that for short half cycle time (360 sec), the silica gel was found to outperform the CPO-27(Ni), this is attributed to the slower kinetics of the CPO-27(Ni). Silica gel had an average cyclic adsorption heat of $33 \mathrm{~kW}$ and a condensation heat of $10 \mathrm{~kW}$ while CPO-27(Ni) has an adsorption heat of $21 \mathrm{~kW}$ and a condensation heat of $3 \mathrm{~kW}$. At longer half cycle times $(3600 \mathrm{sec})$, silica gel and CPO-27(Ni) had similar energy recovery from the condenser and the adsorption bed. The energy that can be stored from the adsorption process was $8 \mathrm{~kW}$ and from the condensation was $3 \mathrm{~kW}$, such amount of heat can be utilized for the heating of buildings where desorption process can be performed using night cheap electricity and the adsorption heat is extracted during day time. Such analysis gives an indication of the effect of the operating time on energy storage performance and the expected performance of $\mathrm{CPO}-27(\mathrm{Ni}) \mathrm{MOF}$ material in comparison to other adsorption materials. This analysis proves that $\mathrm{CPO}-27(\mathrm{Ni})$ is more suitable for longer cycle times.

The energy density of the two materials (CPO-27(Ni) and silica gel-RD) were compared to others materials used previously by other researchers. The materials and the charging temperatures used are listed in Table 3. It can be seen from Fig. 9 and Table 3 that CPO-27(Ni) outperformed other materials Zeolite 13X [44], SWS-1L [45], Zeolite 5A [35]. CPO-27(Ni) was only surpassed by Zeolite $13 \mathrm{X}$ [25] which can be attributed to the high charging temperature used in that study. 
Fig.10a and $\mathbf{b}$ show the effect of the cooling water temperature of the condenser and the adsorption bed on the amount of the energy that can be stored using CPO-27(Ni). The effect of the regeneration temperature was also shown in both figures. At a constant regeneration temperature, it can be noticed that decreasing the cooling water temperature gives a higher amount of energy from the condenser and the adsorption bed. For the condenser, decreasing the cooling water temperature leads to the decrease partial pressure ratio between condenser and desorber resulting in the cyclic water vapour uptake which increases the adsorbate water circulated and hence a higher amount of energy generated from the condenser. For the adsorption bed, decreasing the cooling water temperature allows a higher relative pressure in the bed and hence a higher water vapour uptake that eventually would increase the amount generated form the bed due to the adsorption process. The figure also shows that a constant cooling water temperature, using a higher regeneration temperature enhances the amount of energy that can be stored and that is due to the higher amount of refrigerant that can circulate through the cycle.

Fig. 10c shows the effect of the chilled water inlet temperature on the performance of the energy storage system using CPO-27(Ni). Generally, increasing the evaporation temperature would increase the amount of heat that can be extracted from the adsorption bed and the condenser. This can be attributed to that by increasing the evaporation temperature would increase the water uptake and hence increase the water circulated in the system. The slight increase in the heat generated which can be stored is due to that the material exhibits a type I that has a very slight dependency on the evaporation temperature. The independency of $\mathrm{CPO}-27(\mathrm{Ni})$ on the evaporation temperature is considered as a remarkable advantage allowing to it work on application with a much wider range of evaporation temperature than other MOFs such MIL-100 or MIL-101 which require high evaporation temperatures.

A comparison between the silica gel and $\mathrm{CPO}-27(\mathrm{Ni})$ at different evaporation temperatures was held. Fig. $10 \mathrm{~d}$ shows that an evaporation temperature of $7^{\circ} \mathrm{C}$, the two materials have the amount of heat that can be stored. At lower evaporation temperatures, the CPO-27(Ni) surpass the silica gel-RD due to that the material exhibits a type I water adsorption isotherm reaching $81 \%$ of its capacity at a very low relative pressure corresponding to low evaporation temperature. This shows that $\mathrm{CPO}-27(\mathrm{Ni})$ is more suitable than silica gel-RD for energy storage applications with low evaporation temperatures while silica gel is more appropriate at evaporation temperatures higher than $7^{\circ} \mathrm{C}$ at the investigated adsorption and regeneration temperatures.

Fig. 11 shows the effect of the adsorption bed size on the energy stored by changing the conductance of reactors relative to initial design, it was found that oversizing the adsorption units is not beneficial in recovering any additional energy and also a larger unit volume and a higher cost are expected. Also, it was observed that the energy recovered from adsorption bed is double that from the condenser. 
Regarding the flow strategy of the cooling water and its effect on the performance of the system, Fig. 12 shows the conventional flow strategy 1, where cooling water is divided between the condenser and the adsorption bed simultaneously. In flow strategy 2, the cooling water enters the adsorption bed first and then goes to the condenser. Table 4 shows that strategy 2 where the cooling water is circulated through the adsorption bed and then the condenser was found to decrease the recovered energy from the condenser by $4 \%$. The difference between the cooling water inlet and outlet temperatures from the condenser for both designs is shown in Fig. 13. As it can be seen, the logarithmic mean temperature difference in the first design is higher than in the second one. This is due to that the cooling water temperature entering the condenser is lower in the first case so the rate of the heat transfer is higher compared to the second one. This will permit a higher amount of energy to be extracted from the condenser. This difference highlights the potential of the importance of the water circulation scheme in energy storage application.

\section{$8 \quad$ Conclusions}

Many studies have been done regarding energy storage applications; most of them were utilizing conventional adsorbents such as zeolites. Metal-organic frameworks are novel materials that offer a great potential for sorption energy storage and cooling applications. A detailed characterization of CPO-27(Ni) MOF material was performed in terms of particle size, surface area, SEM, XRD and water adsorption characteristics. The XRD pattern and water adsorption isotherms were predicted using Materials Studio software. The measured data were used in Simulink / Nist refprop platform to model a two bed adsorption system where the amount of energy recovered from the adsorption bed and the condenser were determined. The CPO-27(Ni) was found to exhibit an energy density of 170 $\mathrm{Wh} / \mathrm{kg}$ (charging temperature of $100^{\circ} \mathrm{C}$ and half cycle time of $3600 \mathrm{~s}$ ) where long cycle time of more than 30 minutes is recommended in energy storage applications. The potential of energy recovered from the adsorption bed is double that recovered from the condenser. Oversizing the adsorption bed was found to be not beneficial in recovering any additional energy but leads to an increase in the cost. Finally, recirculating the cooling water through the adsorption bed and then the condenser was found to decrease the recovered energy from the condenser by $4 \%$.

\section{Acknowledgement}

The authors would like to thank Innovate UK (Grant Number 131498) and the Engineering and Physical Sciences Research Council -EPSRC (Grant number EP/L505882/1) for sponsoring the project.

\section{Nomenclature}

$\begin{array}{llll}\mathrm{A} & \text { Area }[\mathrm{m} 2] & \mathrm{m} & \text { Mass flow rate }[\mathrm{kg} / \mathrm{s}] \\ \mathrm{C} & \text { Specific heat }[\mathrm{kJ} / \mathrm{kg}] & \mathrm{R} & \text { Universal gas constant }=8.314\left[\mathrm{~J} \mathrm{~mol}^{-1} \mathrm{~K}^{-1}\right] \\ \mathrm{D}_{\mathrm{so}} & \text { Surface diffusion constant }\left[\mathrm{m}^{2} \mathrm{~s}^{-1}\right] & \mathrm{R}_{\mathrm{p}} & \text { Particle radius }[\mathrm{m}] \\ \mathrm{Ea} & \text { Activation Energy }\left[\mathrm{J} \mathrm{mol}^{-1}\right] & \mathrm{T} & \text { temperature }[\mathrm{K}] \\ \mathrm{H}_{\mathrm{ads}} & \text { Heat of adsorption }\left[\mathrm{kJkg}^{-1}\right] & \mathrm{U} & \text { Overall heat transfer coefficient }\left[\mathrm{Wm}^{-2} \mathrm{~K}^{-1}\right]\end{array}$


Fp Particle shape factor

M Mass [kg]

\section{Subscript}

al Aluminium

ads Adsorbent, adsorber

chill Chilled

$\mathrm{cu} \quad$ Copper

cond Condenser

evap Evaporator $\mathrm{x}_{\mathrm{eq}} \quad$ Equilibrium uptake $\left[\mathrm{kg} / \mathrm{kg}_{\text {ads }}\right]$

$\mathrm{X}$ Instantaneous uptake $\left[\mathrm{kg} / \mathrm{kg}_{\text {ads }}\right]$

$\begin{array}{ll}\text { des } & \text { Desorber } \\ \text { in } & \text { Inlet } \\ \text { 1 } & \text { Liquid } \\ \text { out } & \text { Outlet } \\ \text { ref } & \text { Refrigerant } \\ \text { w } & \text { water } \\ \text { v } & \text { Vapour }\end{array}$




\section{References}

[1] X. Xu, X. Lao, J. Wu, Y. Zhang, X. Xu, K. Li, Synthesis and characterization of $\mathrm{Al}_{2} \mathrm{O}_{3} / \mathrm{SiC}$ composite ceramics via carbothermal reduction of aluminosilicate precursor for solar sensible thermal storage, Journal of Alloys and Compounds 662 (2016) 126-137.

[2] V. A. Salomoni, C. E. Majorana, G. M. Giannuzzi, A. Miliozzi, R. Di Maggio, F. Girardi, D. Mele, M. Lucentini, Thermal storage of sensible heat using concrete modules in solar power plants, Solar Energy 103 (2014) 303-315.

[3]S. Ushak, A. G. Fernández, M. Grageda, Using molten salts and other liquid sensible storage media in thermal energy storage (TES) systems, Advances in Thermal Energy Storage Systems, (2015) 4963.

[4] S. Kuravi, J. Trahan, D.Y. Goswami, M.M. Rahman, E.K. Stefanakos, Thermal energy storage technologies and systems for concentrating solar power plants, Prog. Energy Combust. Sci. 39 (2013) 285-319.

[5] A. Mawire, Performance of Sunflower Oil as a sensible heat storage medium for domestic applications, Journal of Energy Storage 5 (2016) 1-9.

[6] M. Esen, T. Ayhan, Development of a model compatible with solar assisted cylindrical energy storage tank and variation of stored energy with time for different phase change materials, Energy Convers. Mgmt 1996; 37: 1775-1785.

[7] L. Jiang, L.W. Wang, X.F. Zhang, C.Z. Liu, R.Z. Wang. Performance prediction on a resorption cogeneration cycle for power and refrigeration with energy storage. Renewable Energy 83 (2015) 1250-1259.

[8] D. Stitou , N. Mazet, S. Mauran . Experimental investigation of a solid/gas thermochemical storage process for solar air-conditioning. Energy 41 (2012) 261-270.

[9] M. Esen, A. Durmus s. Durmus, Geometric design of solar-aided latent heat store depending on various parameters and phase change materials, Solar Energy 1998; 62:19-28.

[10] M. Esen, Thermal performance of a solar-aided latent heat store used for space heating by heat pump, Solar Energy 2000; 69:15-25.

[11] Q. Mao, Recent developments in geometrical configurations of thermal energy storage for concentrating solar power plant, Renewable and Sustainable Energy Reviews 2016; 59: 320-327.

[12] S. Kuravi, J. Trahan, D. Goswami, M. Rahman, E. Stefanakos.Thermal energy storage technologies and systems for concentrating solar power plants, Prog. Energy Combust. Sci. 2013;39:285-319.

[13] B. Cárdenas, N. León.High temperature latent heat thermal energy storage: phase change materials, design considerations and performance enhancement techniques. Renew Sustain Energy Rev 2013;27:724-37. 
[14] S. Jegadheeswaran, S. Pohekar, Performance enhancement in latent heat thermal storage system: a review. Renew Sustain Energy Rev 2009; 13:2225-44.

[15] F. Agyenim, N. Hewitt, P. Eames, M. Smyth. A review of materials, heat transfer and phase change problem formulation for latent heat thermal energy storage system (LHTESS). Renew Sustain Energy Rev2010;14:615-28.

[16] P. Pinel, C. Cruickshank, I. Beausoleil-Morrison, A. Wills. A review of available methods for seasonal storage of solar thermal energy in residential application. Renew Sustain Energy Rev 2011;15:3341-59.

[17] L. Jiang, F.Q. Zhu, L.W. Wang, C.Z. Liu, R.Z. Wang, Experimental investigation on a $\mathrm{MnCl}_{2^{-}}$ $\mathrm{CaCl}_{2}-\mathrm{NH}_{3}$ thermal energy storage system, Renewable Energy 91 (2016) 130-136.

[18] I. Sarbu, C. Sebarchievici. General review of solar-powered closed sorption refrigeration systems. Energy Convers. Manage. 105 (2015) 403-422.

[19] A. Lass-Seyoum, M. Blicker, D. Borozdenko, T. Friedrich, T. Langhof. Transfer of laboratory results on closed sorption thermochemical energy storage to a large-scale technical system. Energy Procedia 30 (2012) 310 - 320.

[20] B. Shi, R. Al-dadah,S. Mahmoud, A. Elsayed, A. Rezk, Mathematical And CFD Modelling for a Rectangular Finned Tube Adsorption Bed for Automotive Cooling, ICAE, 2013.

[21] H. Hassan, A. Mohamad, A review on solar-powered closed physisorption cooling systems, Renewable Sustainable Energy Rev. 16 (2012) 2516-2538.

[22] A. Rezk , R. Al-dadah, S. Mahmoud, A. Elsayed , Investigation of Ethanol/metal organic frameworks for low temperature adsorption cooling applications, Appl. Energy 112 (2013) 10251031.

[23] S. Henninger, F. Jeremias, H. Kummer, P. Schossig, H. Henning, Novel sorption materials for solar heating and cooling. Energy Procedia 30 (2012) 279 - 288.

[24] S. Narayanan, S. Yang, H. Kim, E. Wang, Optimization of adsorption processes for climate control and thermal energy storage. Int. J. Heat Mass Transfer 77 (2014) 288-300.

[25] M. Duquesne, J. Toutain, A. Sempey, S. Ginestet, E. P. del Barrio, Modeling of a nonlinear thermochemical energy storage by adsorption on zeolites, Applied Thermal Engineering 2014; 71: 469-480.

[26] X. Zheng, T.S. Ge, R.Z. Wang, Recent progress on desiccant materials for solid desiccant cooling systems. Energy 74 (2014) 280-294.

[27] J. Kim, S. Yeo, J. Jeon, S. Kwak, Enhancement of hydrogen storage capacity and hydrostability of metal-organic frameworks (MOFs) with surface-loaded platinum nanoparticles and carbon black. Microporous Mesoporous Mater. 202 (2015) 8-15.

[28] B. Mettea, H. Kerskes, H. Drück. Concepts of long-term thermochemical energy storage for solar thermal applications - Selected examples. Energy Procedia 30 ( 2012 ) $321-330$. 
[29] H. Wu, S. Wang, D. Zhu. Effects of impregnating variables on dynamic sorption characteristics and storage properties of composite sorbent for solar heat storage. Sol Energ 81 (2007) 864-871

[30] D. Aydin, S. Casey, S. Riffat. The latest advancements on thermochemical heat storage systems. Renewable Sustainable Energy Rev.41 (2015) 356-367.

[31] S. Narayanan, X. Li, S. Yang, H. Kim, A. Umans, Ian S. McKay, Evelyn N. Wang. Thermal battery for portable climate control. Appl. Energy 149 (2015) 104-116.

[32] J. Xu, R. Wang, Y. Li. A review of available technologies for seasonal thermal energy storage. Sol. Energy 103 (2014) 610-638.

[33]A. Solé, I. Martorell, L. Cabez. State of the art on gas-solid thermochemical energy storage systems and reactors for building applications. Renewable Sustainable Energy Rev. 47 (2015) 386-398.

[34] K. N'Tsoukpoe , G. Restuccia, T. Schmidt, X. Py. The size of sorbents in low pressure sorption or thermochemical energy storage processes. Energy 77 (2014) 983-998.

[35] C. Finck, E. Henquet, C. Soest, H. Oversloot,A. de Jong, R Cuypers, H. Spijker .Experimental results of a $3 \mathrm{kWh}$ thermochemical heat storage module for space heating application. Energy Procedia 48 (2014) 320-326.

[36] H. Wu, S. Wang, D. Zhu, Y. Ding. Numerical analysis and evaluation of an open-type thermal storage system using composite sorbents. Int. J. Heat Mass Tran 52 (2009) 5262-5265.

[37] J. Janchen, H. Stach. Shaping adsorption properties of nano-porous molecular sieves for solar thermal energy storage and heat pump applications. Sol. Energy 104 (2014) 16-18

[38] M. Duquesne, J. Toutain, A. Sempey, S. Ginestet, E. del Barrio. Modeling of a nonlinear thermochemical energy storage by adsorption on zeolites. Appl. Therm. Eng. 71 (2014) 469-480

[39] G. Li, S. Qian, H. Lee, Y. Hwang, R. Radermacher. Experimental investigation of energy and exergy performance of short term adsorption heat storage for residential application. Energy 65 (2014) 675-691

[40] J. Ehrenmann, S. Henninger, C. Janiak, Water Adsorption Characteristics of MIL-101 for HeatTransformation Applications of MOFs. Short Communication, Eur. J. Inorg. Chem. 4 (2011) 471474.

[41] A. Elsayed, R. Al-Dadah, S. Mahmoud, A. Elshaer, J. Bowen. Investigation of Efficient Adsorbents using Transient Analysis of Adsorption Chillers with Simulink. HTFF'14, 2014.

[42] A. Akahira, K. Alam, Y. Hamamoto, A. Akisawa, T. Kashiwagi. Mass recovery adsorption refrigeration cycle-improving cooling capacity. Int. J. Refrig (2004). 27, 225-234.

[43] B. Saha, E. Boelman, T. Kashiwagi. Computer Simulation of a silica gel-water adsorption refrigeration cycle-The influence of operating conditions on cooling output. ASHRAE Transactions: Research, 101(1) (1995) 348-357. 
[44] J. Jänchen, D. Ackermann, H. Stach, W. Brösicke, Studies of the water adsorption on Zeolites and modified mesoporous materials for seasonal storage of solar heat, Solar Energy, 2004; 76: 339344.

[45] C. Bales, Thermal properties of materials for thermo-chemical storage of solar heat. IEA-SHC task 32 report B2 of subtask B "Chemical and sorption storage". 


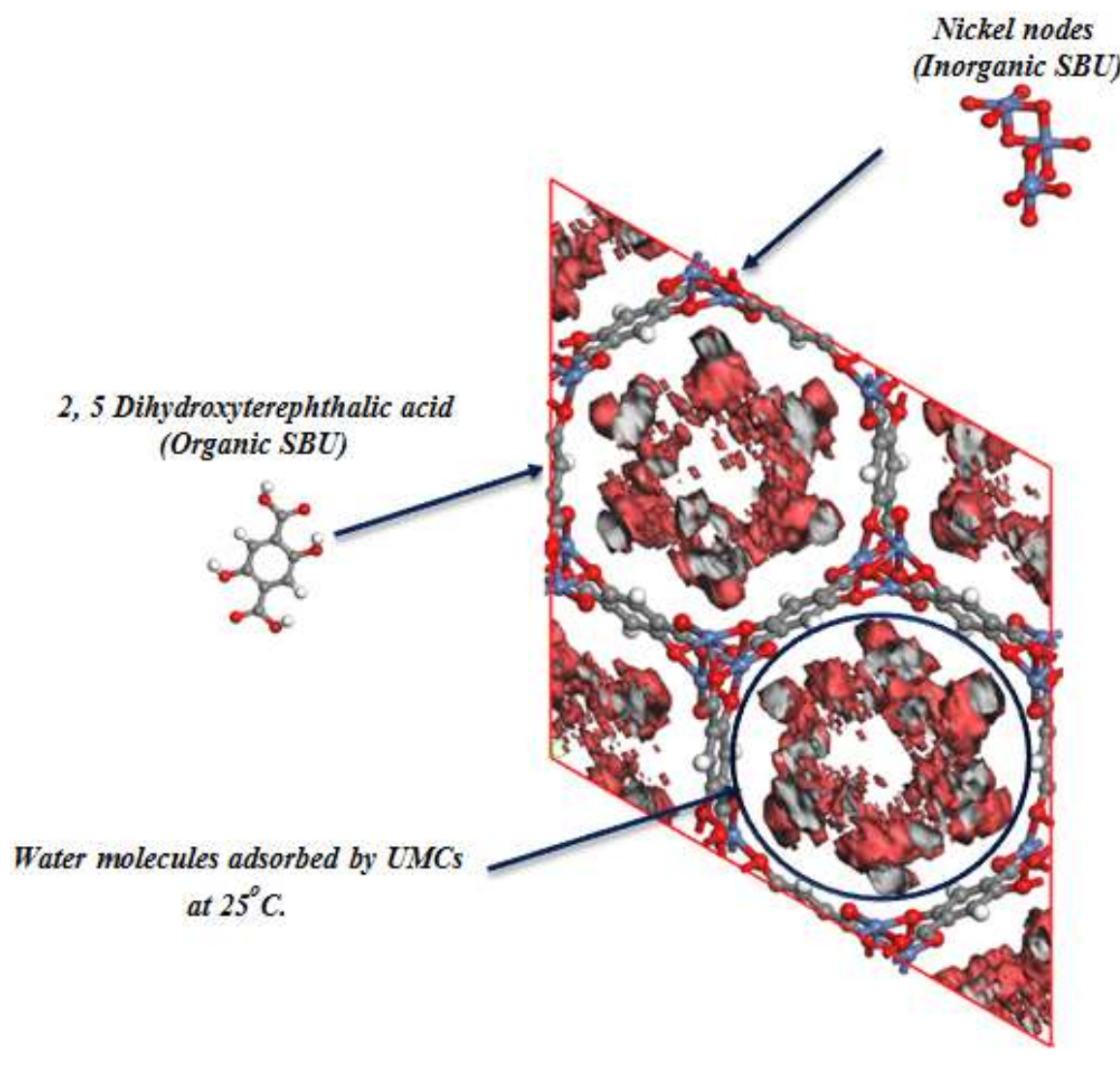

Fig. 1a 


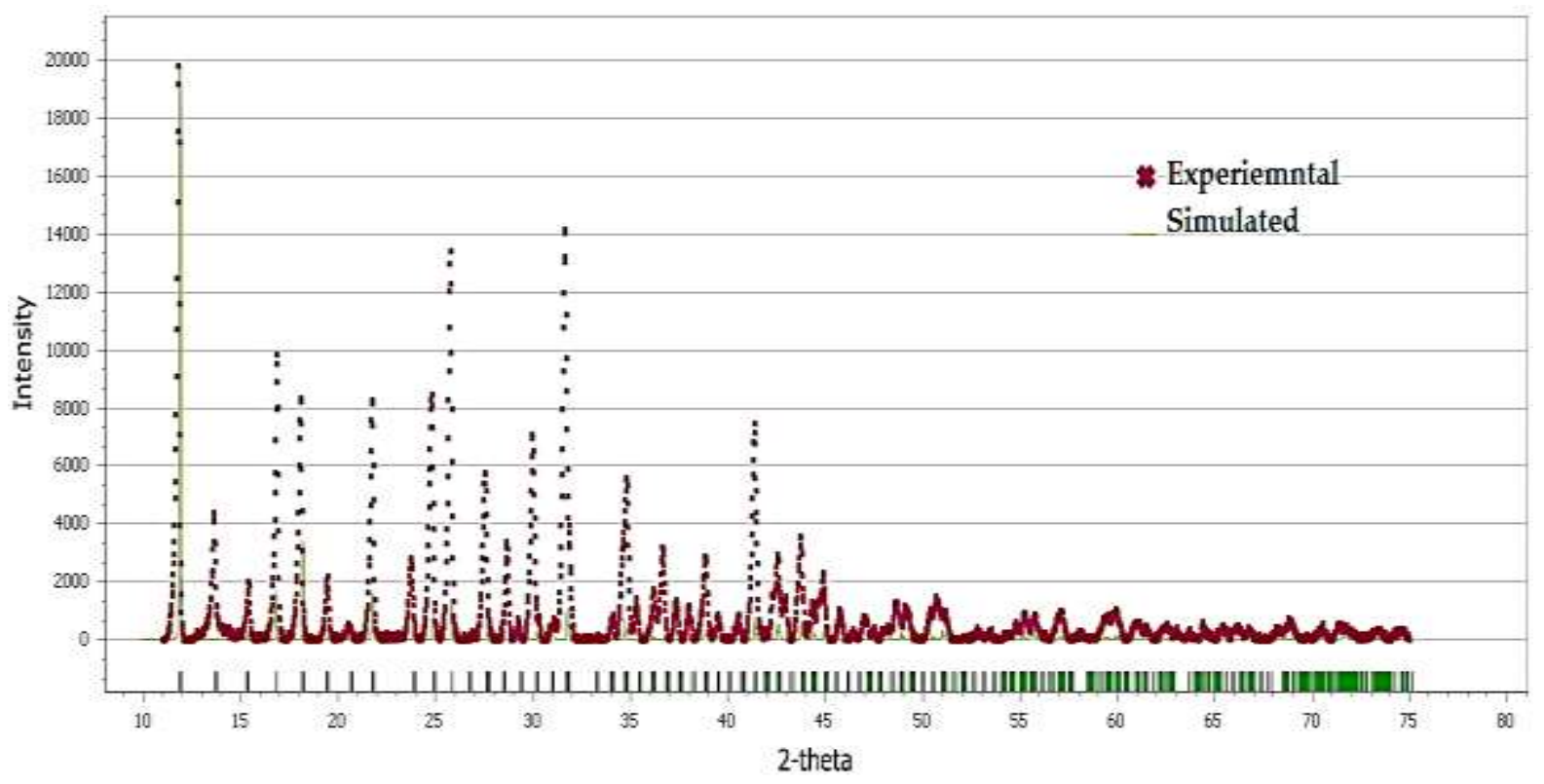

Fig. 1b 

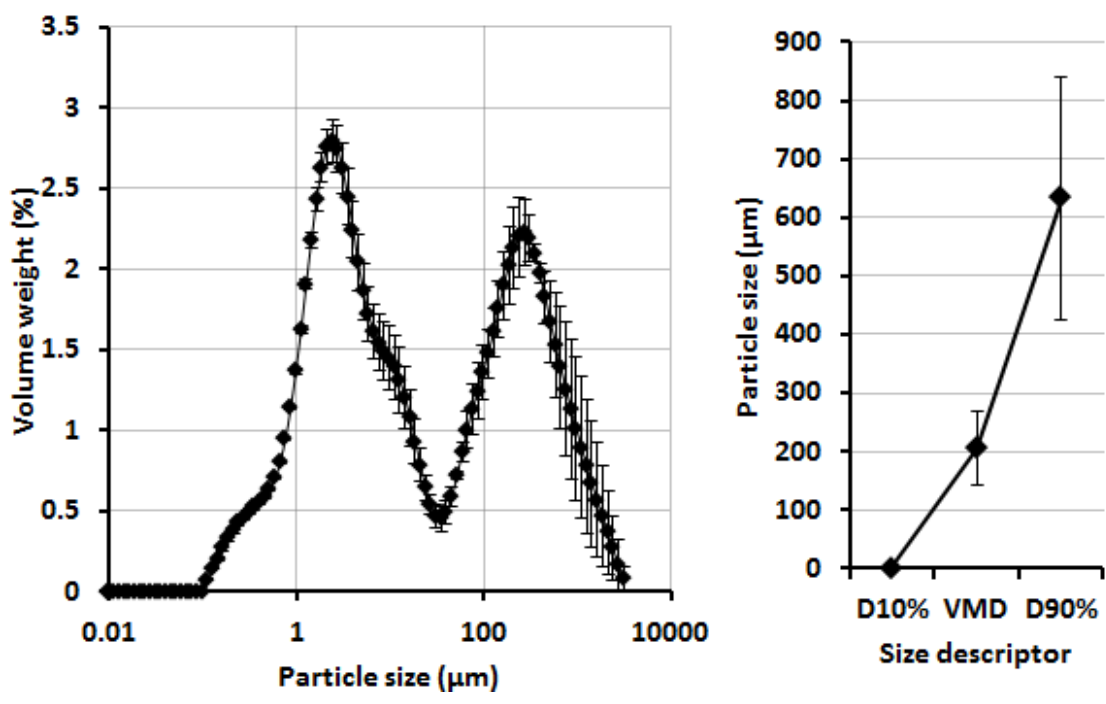

Fig. 1c 


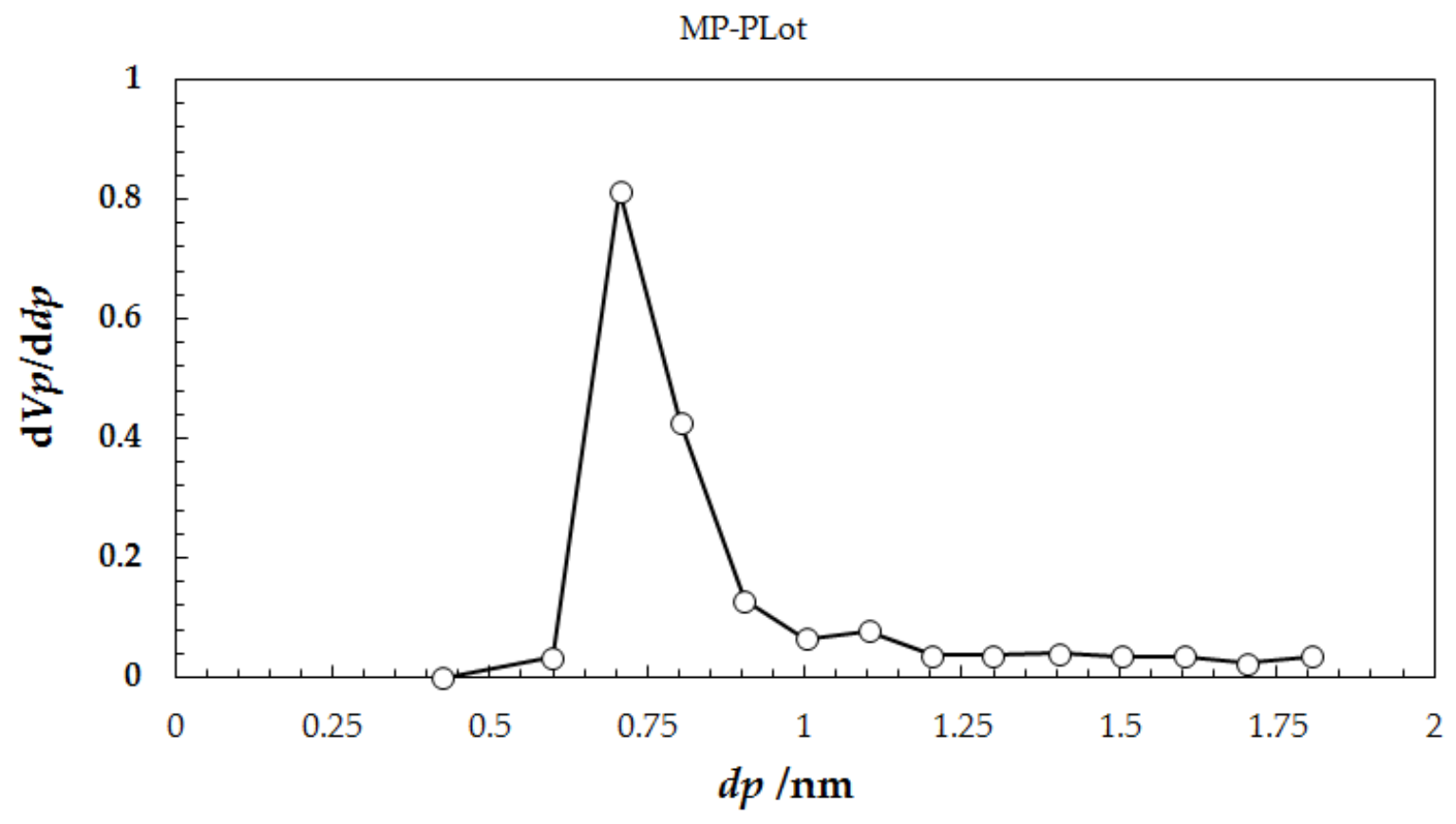

Fig. 2 


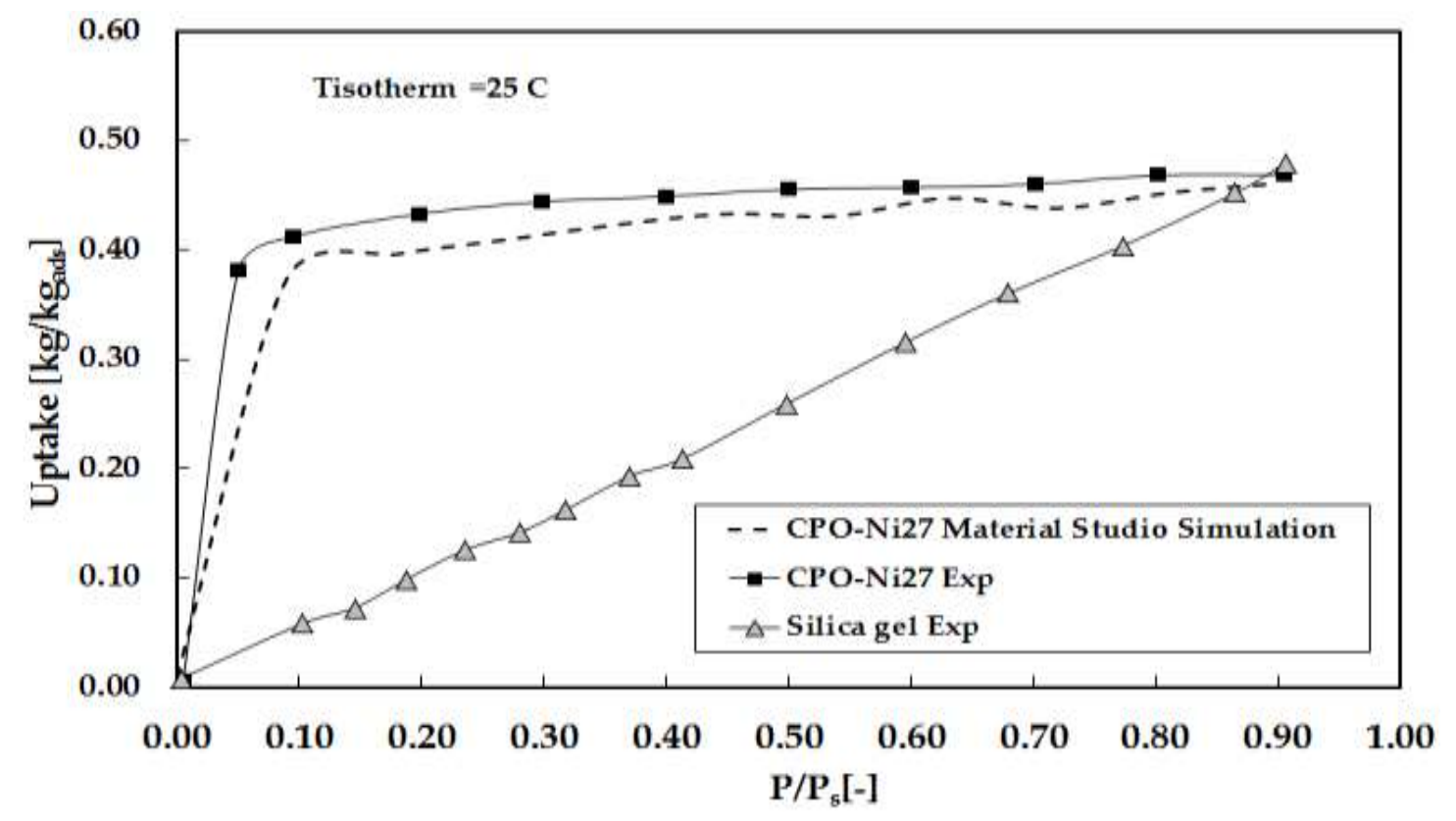

Fig. 3a 


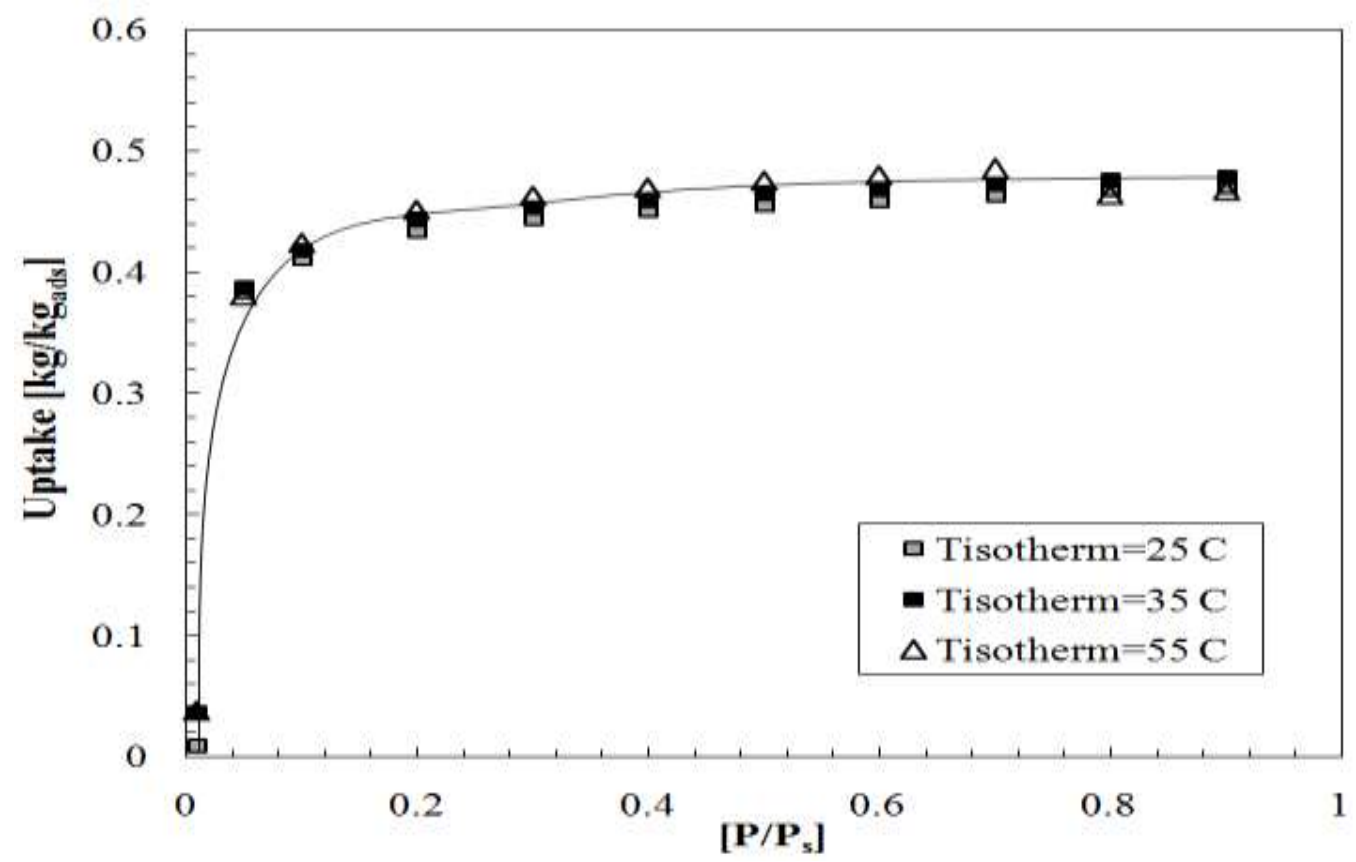

Fig. 3b 


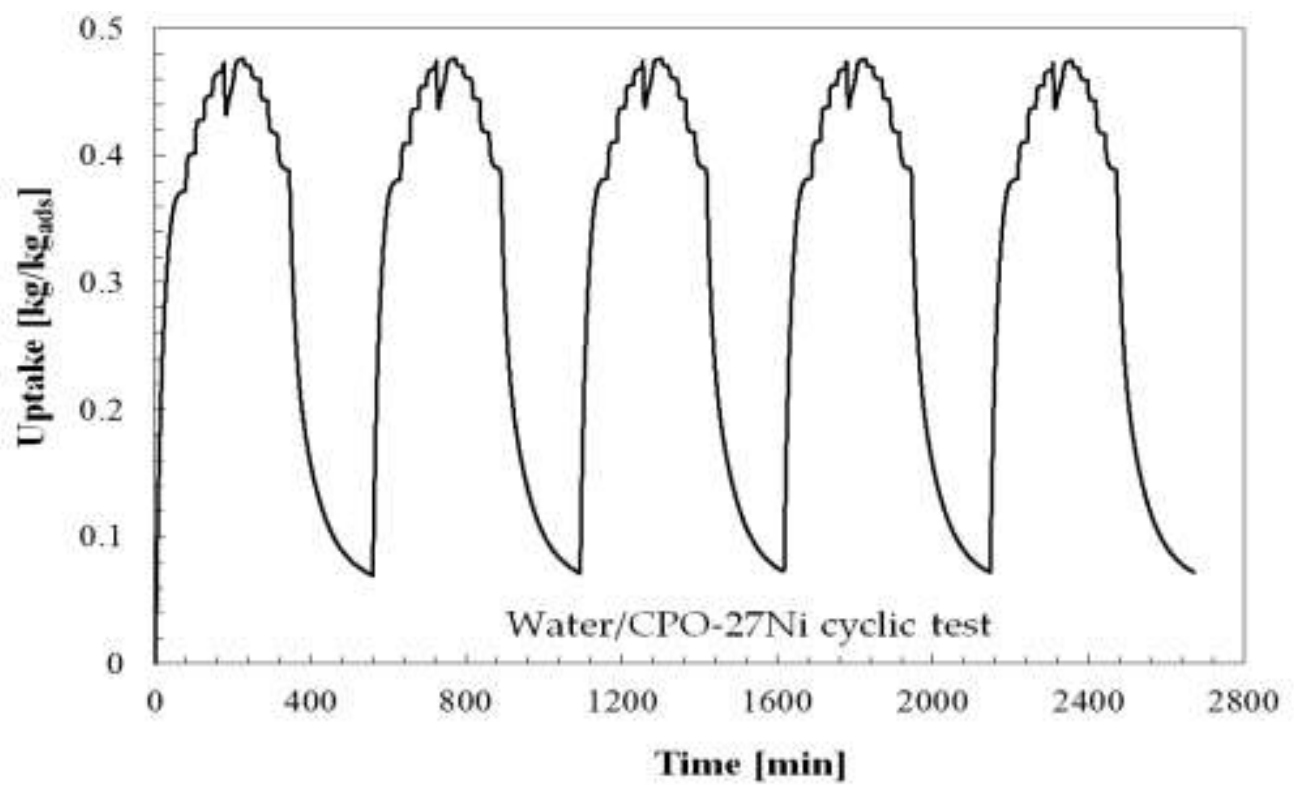

Fig. 4 


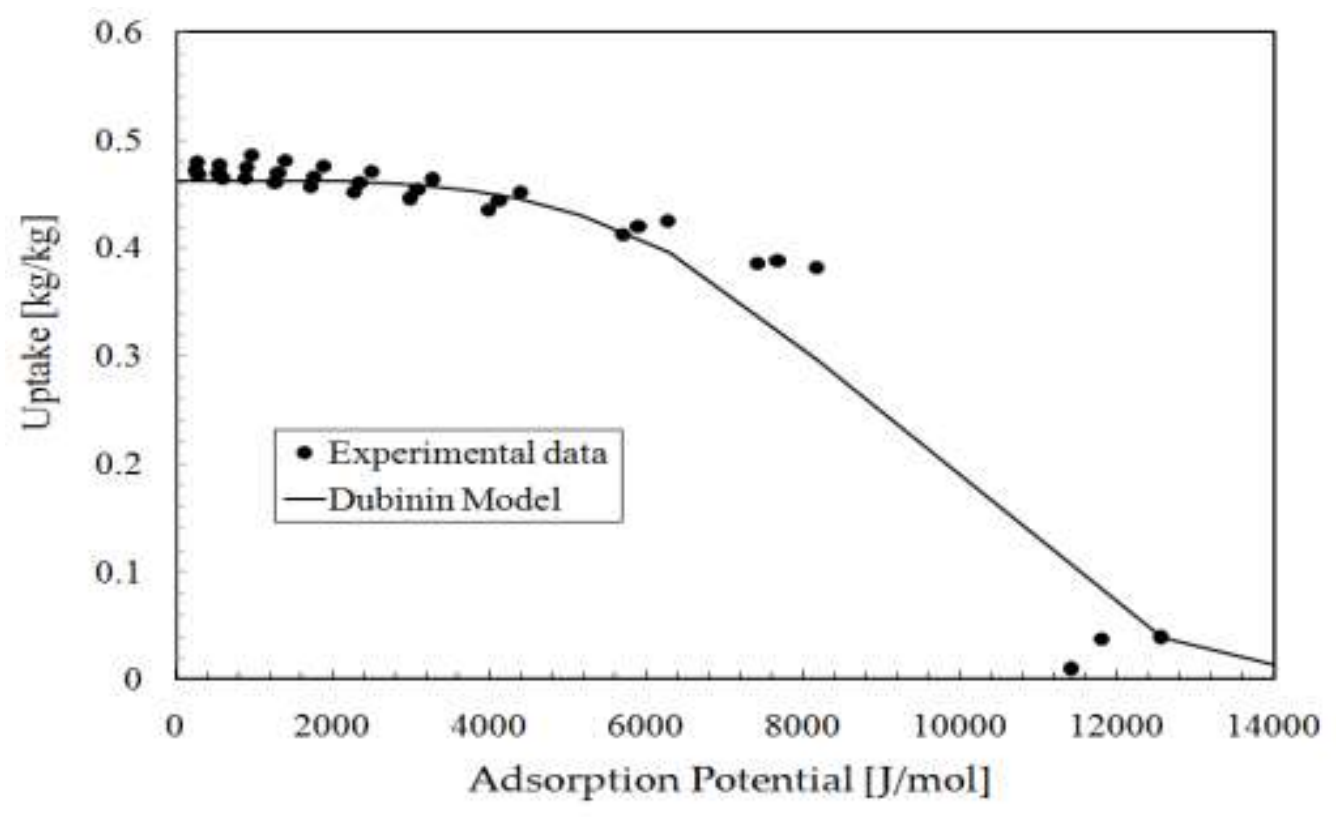

Fig. 5 


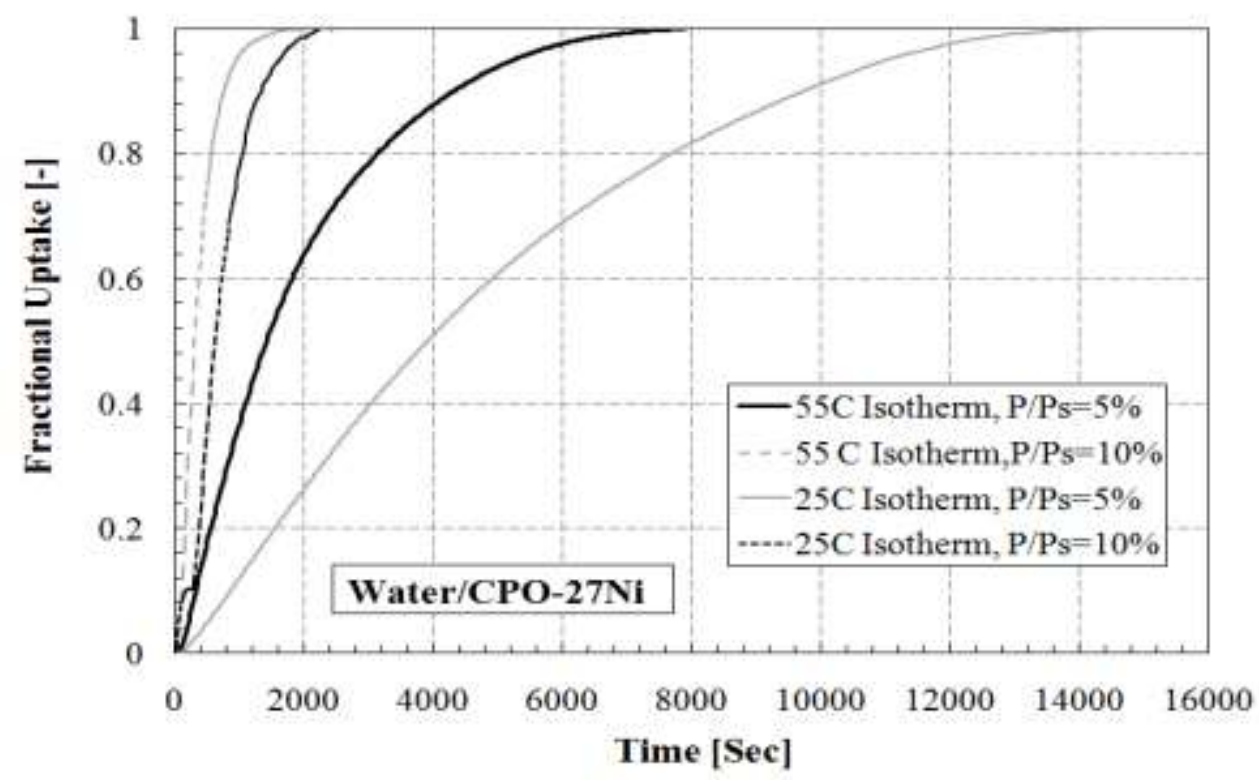

Fig. 6 


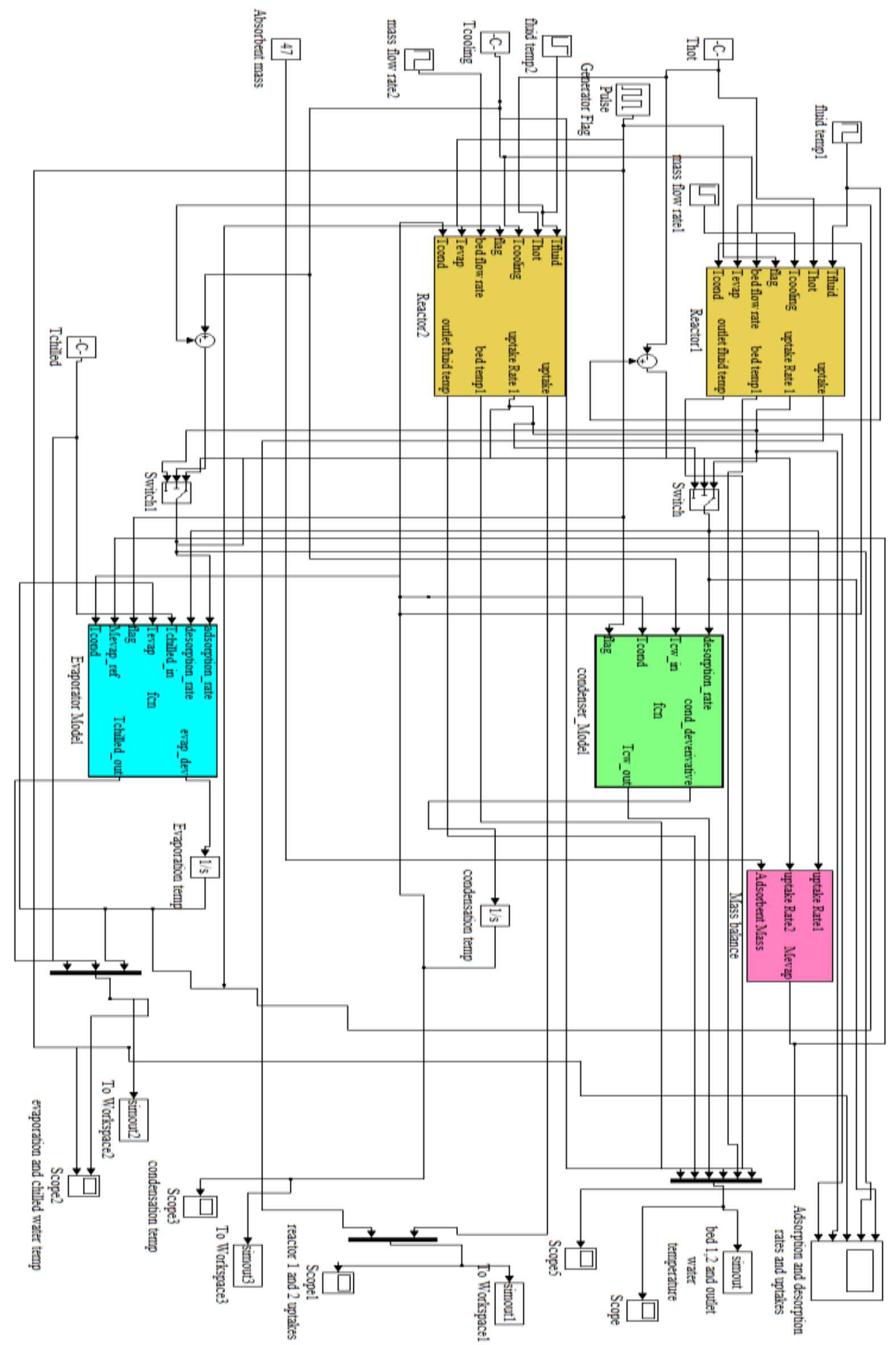

Fig. 7a 


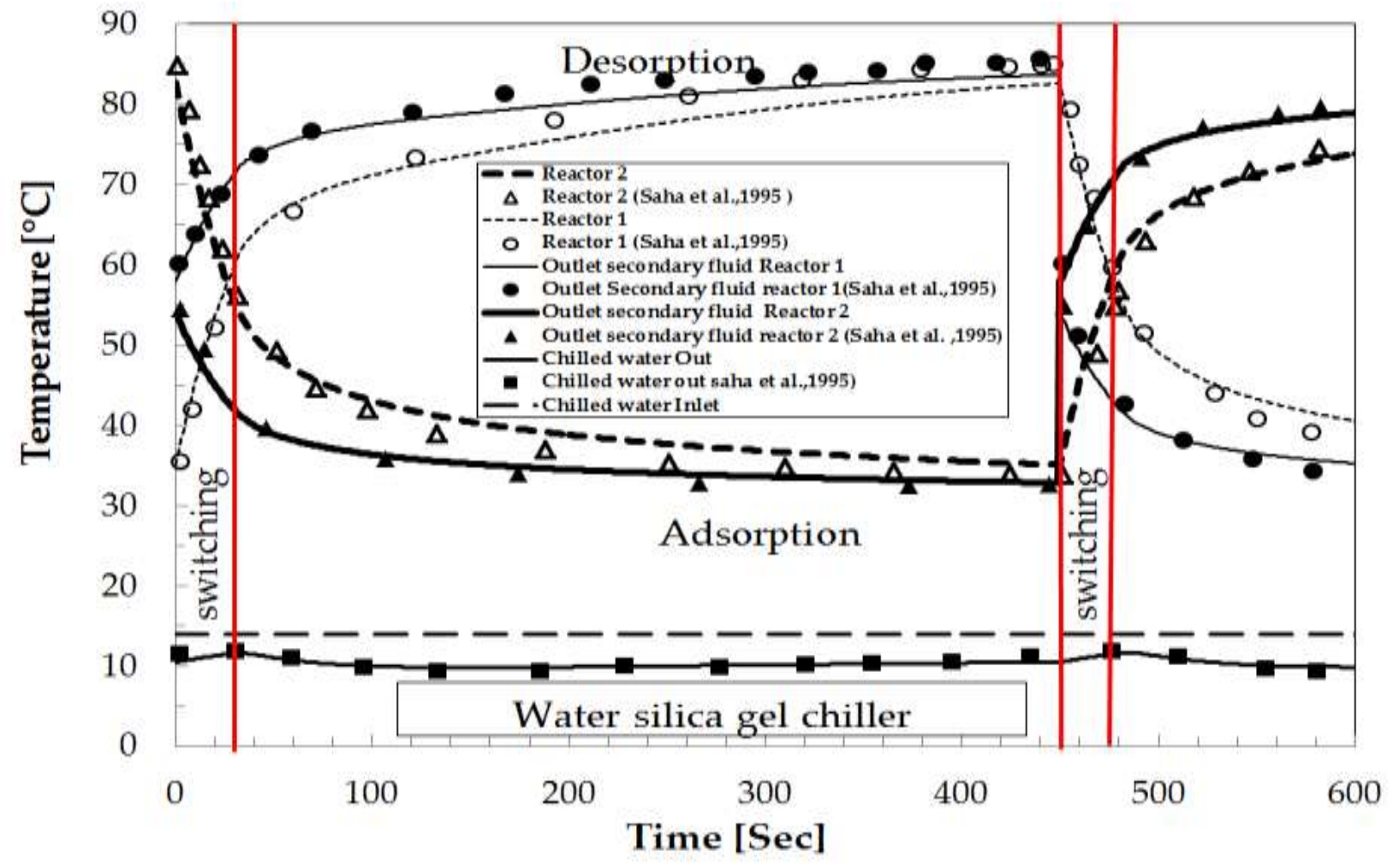

Fig. 7b 

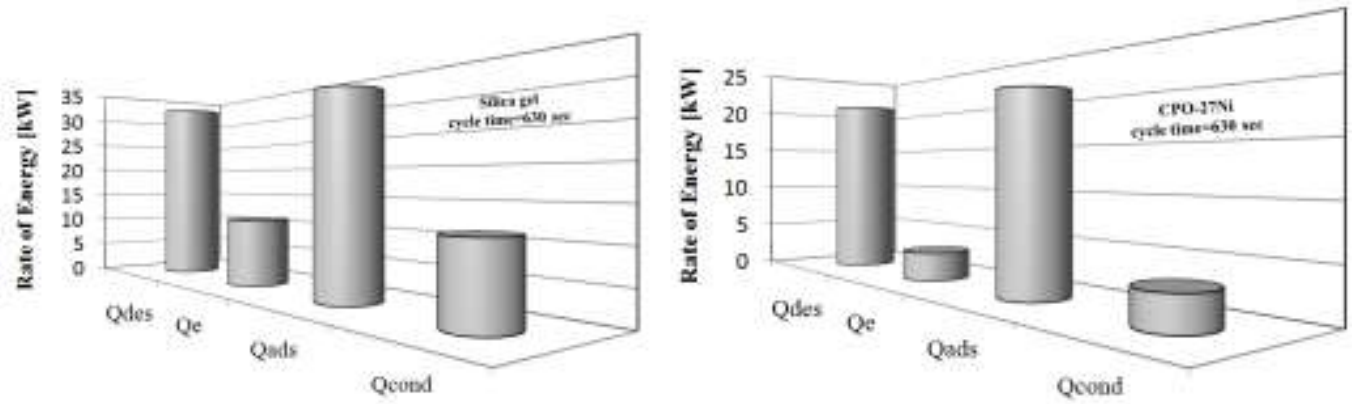

(a) Silica gel (half cycle time of $630 \mathrm{sec}$ )

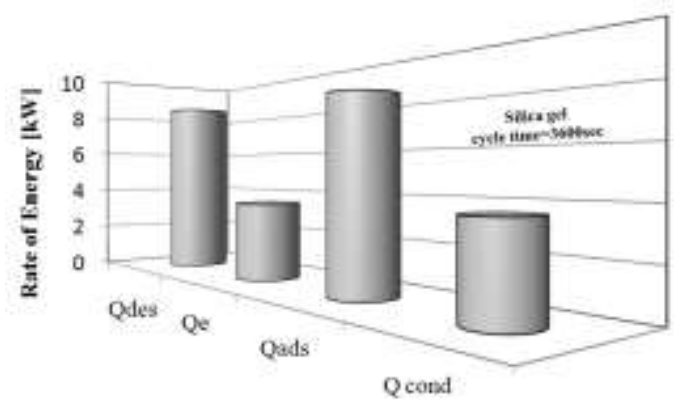

(b) $\mathrm{CPO}-27(\mathrm{Ni})$ (half cycle time of $630 \mathrm{sec}$ )

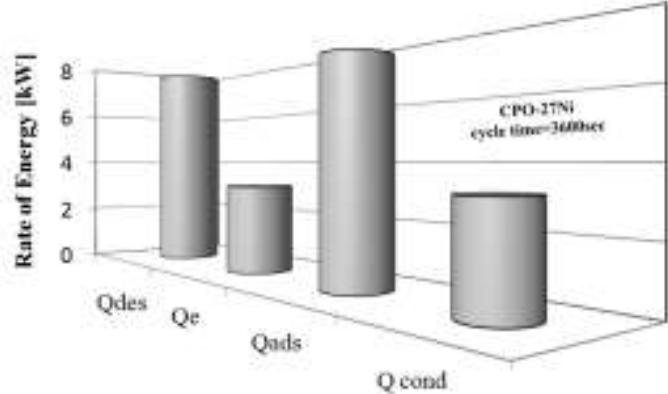

(c) Silica gel (half cycle time of $3600 \mathrm{sec}$ )

(d) CPO-27Ni (half cycle time of $3600 \mathrm{sec}$ )

Fig. 8. 


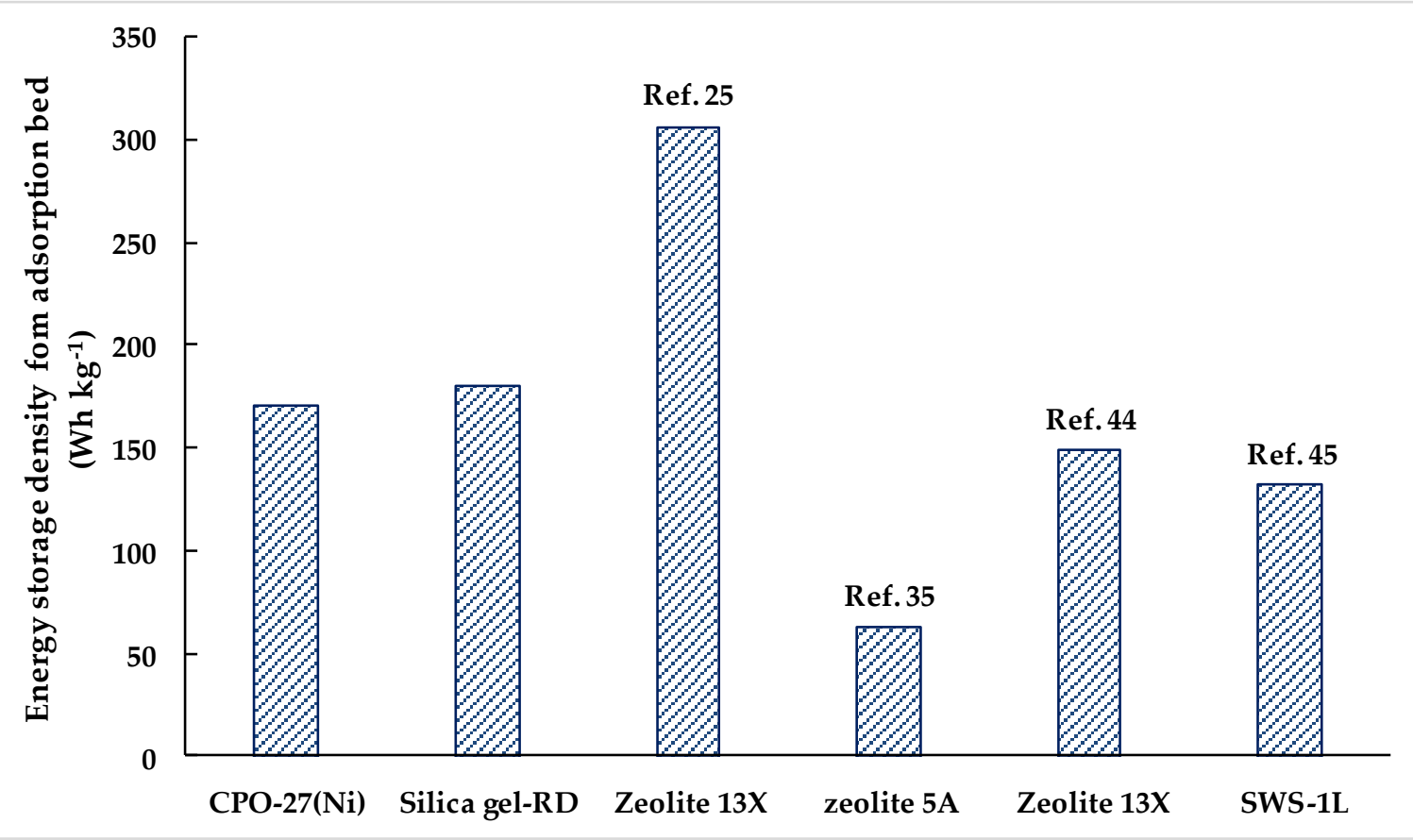

Fig. 9. 


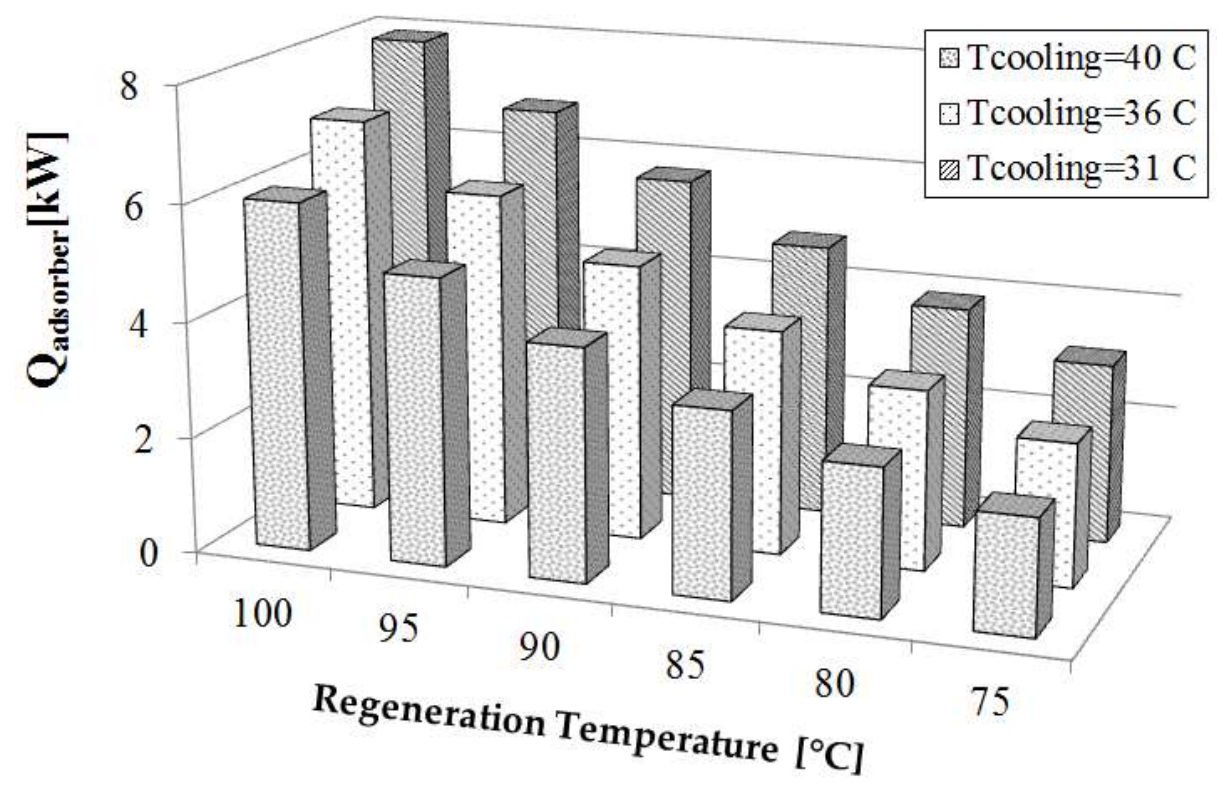

Fig. 10a.

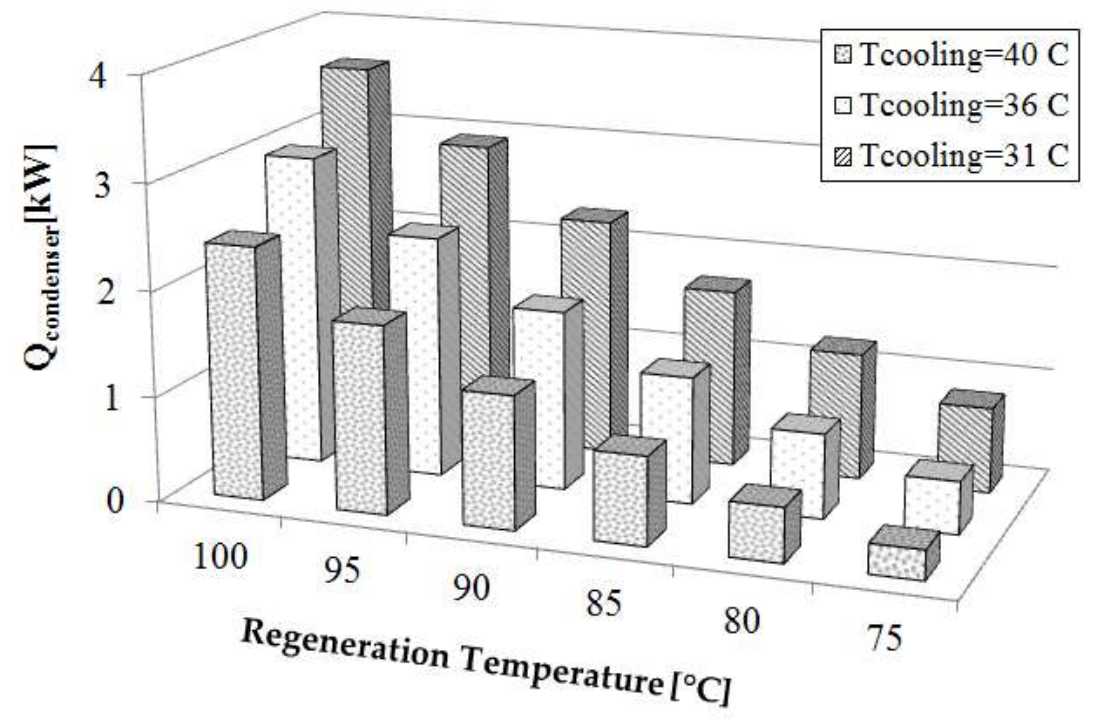

Fig. $10 b$. 


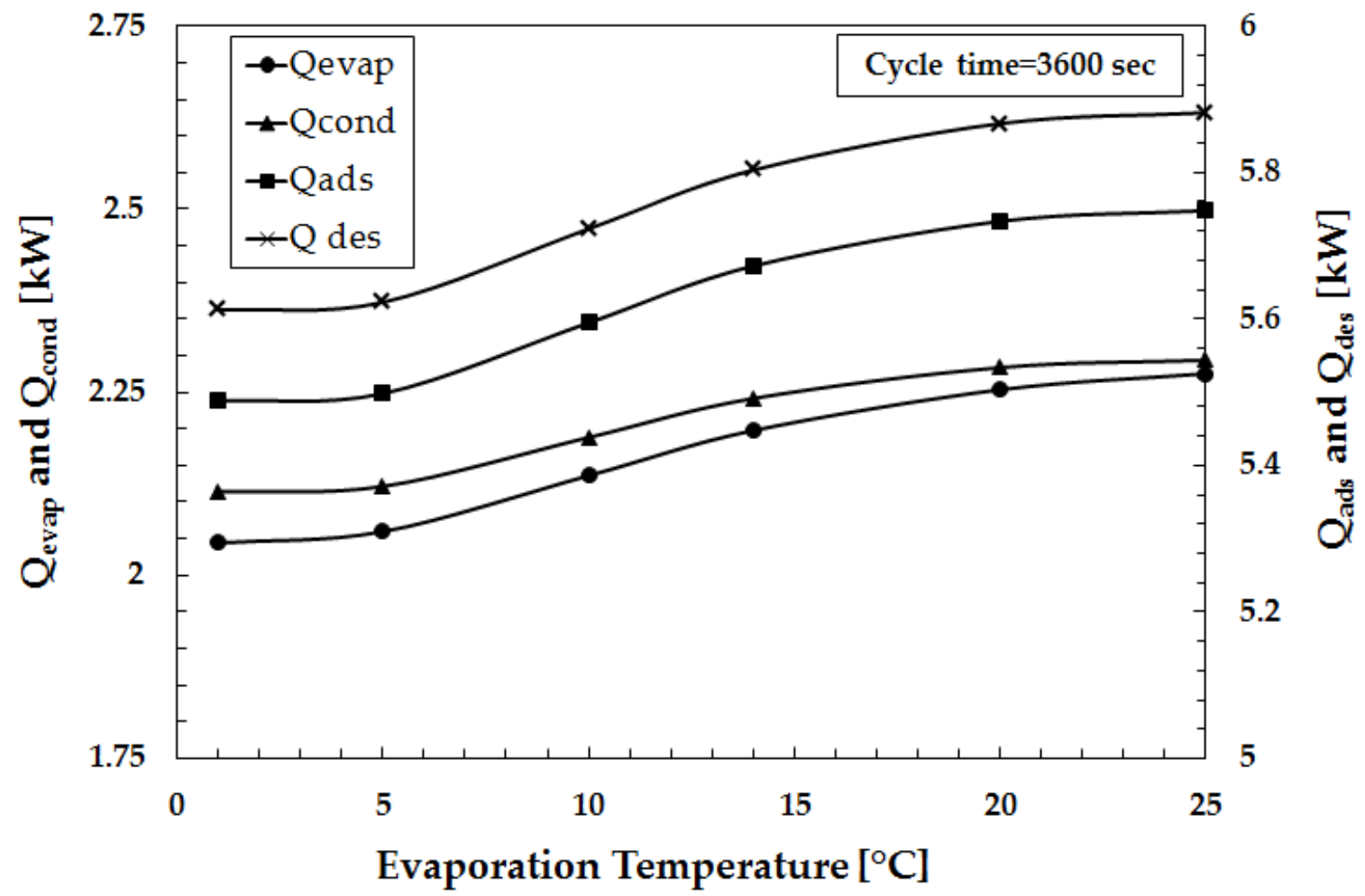

Figure 10c. 


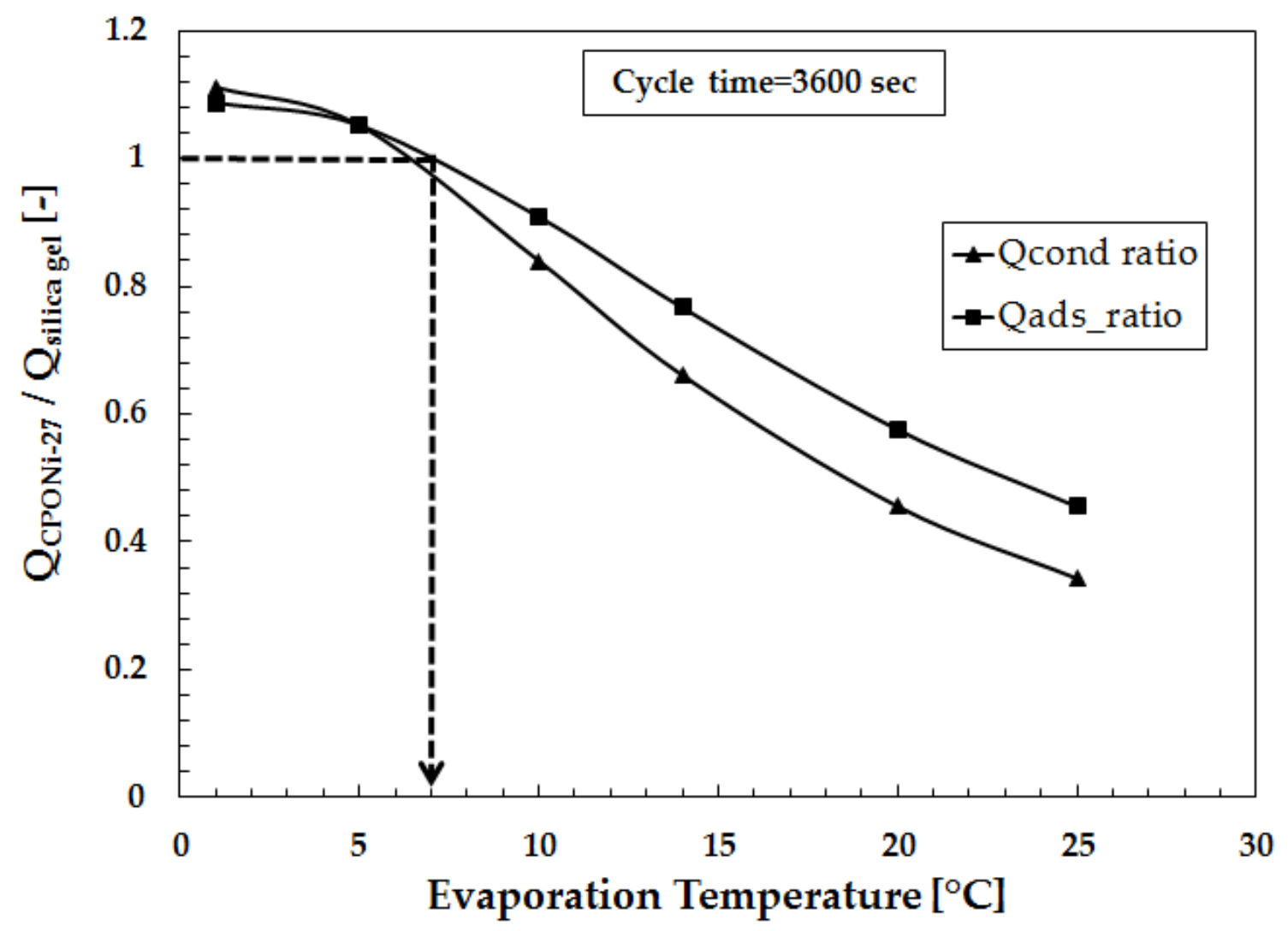

Figure 10d. 


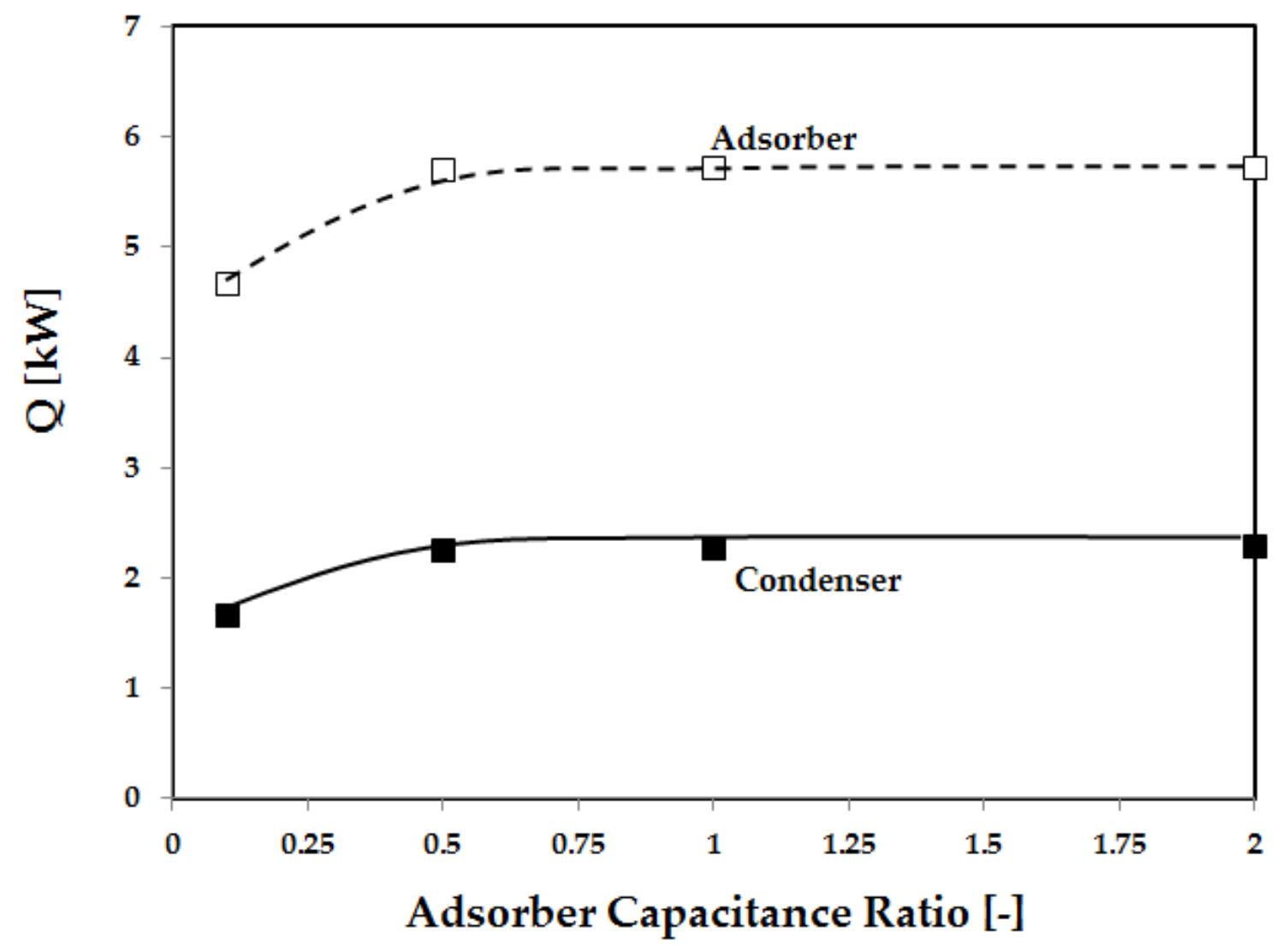

Fig. 11. 


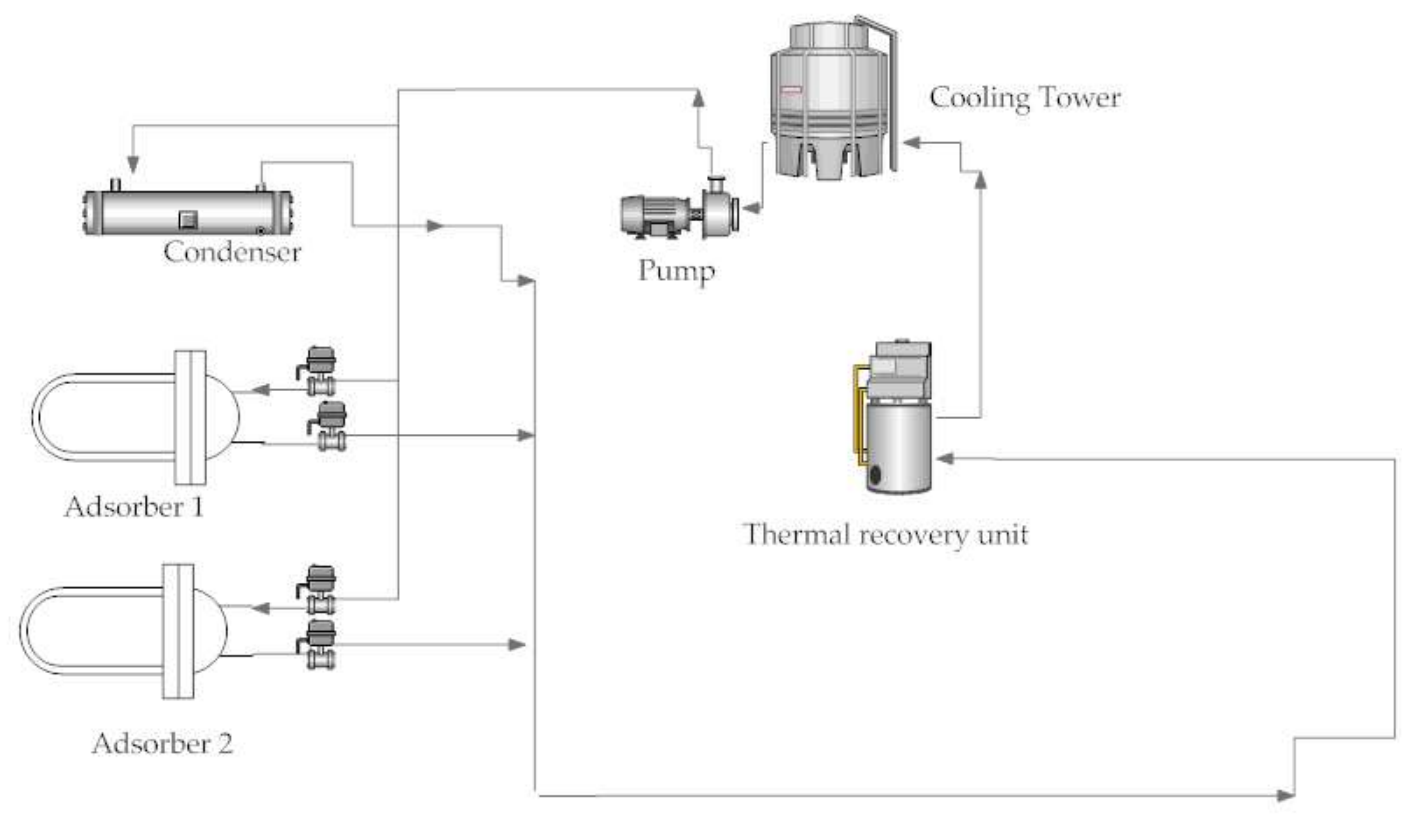

(a) Flow strategy 1

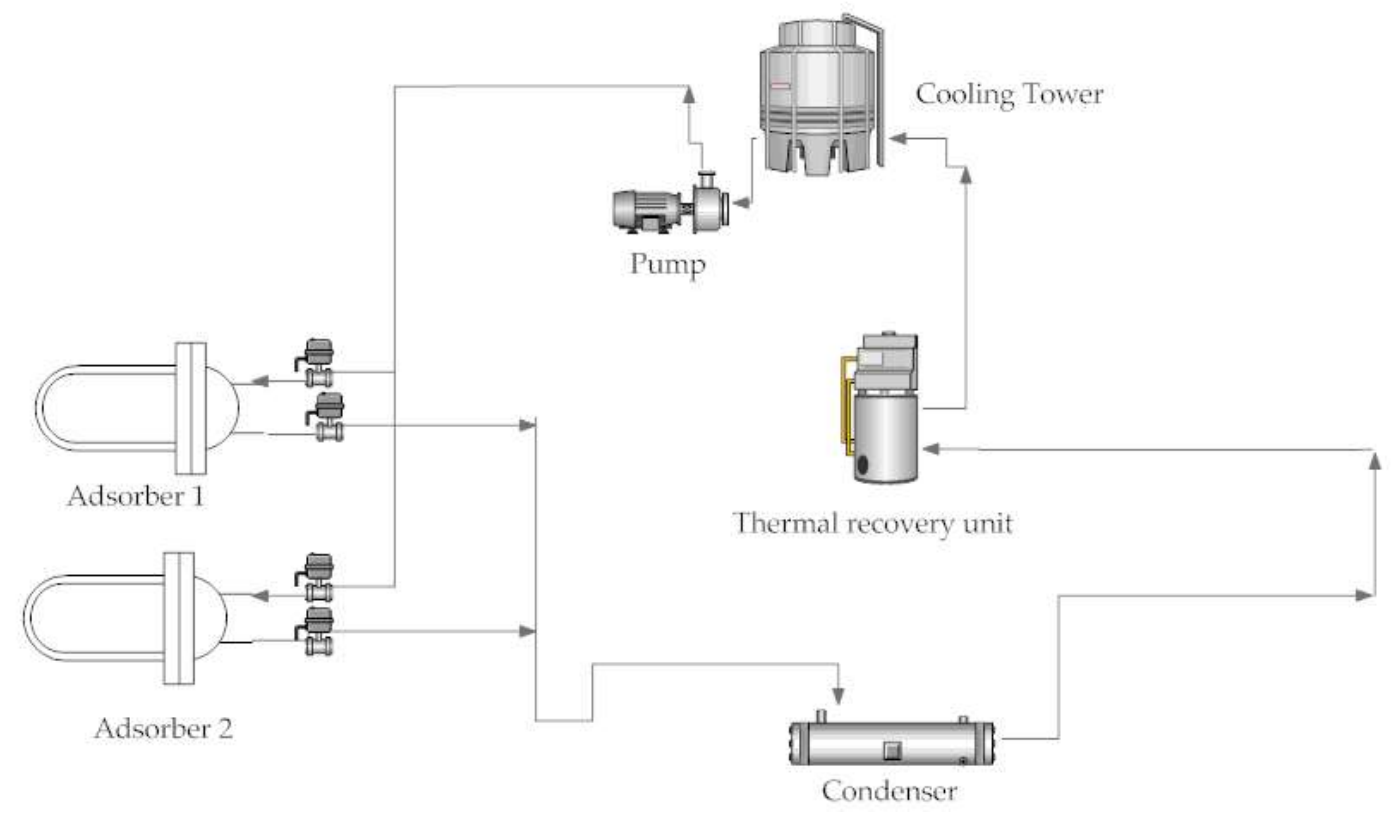

(b) Flow strategy 2

Fig. 12. 


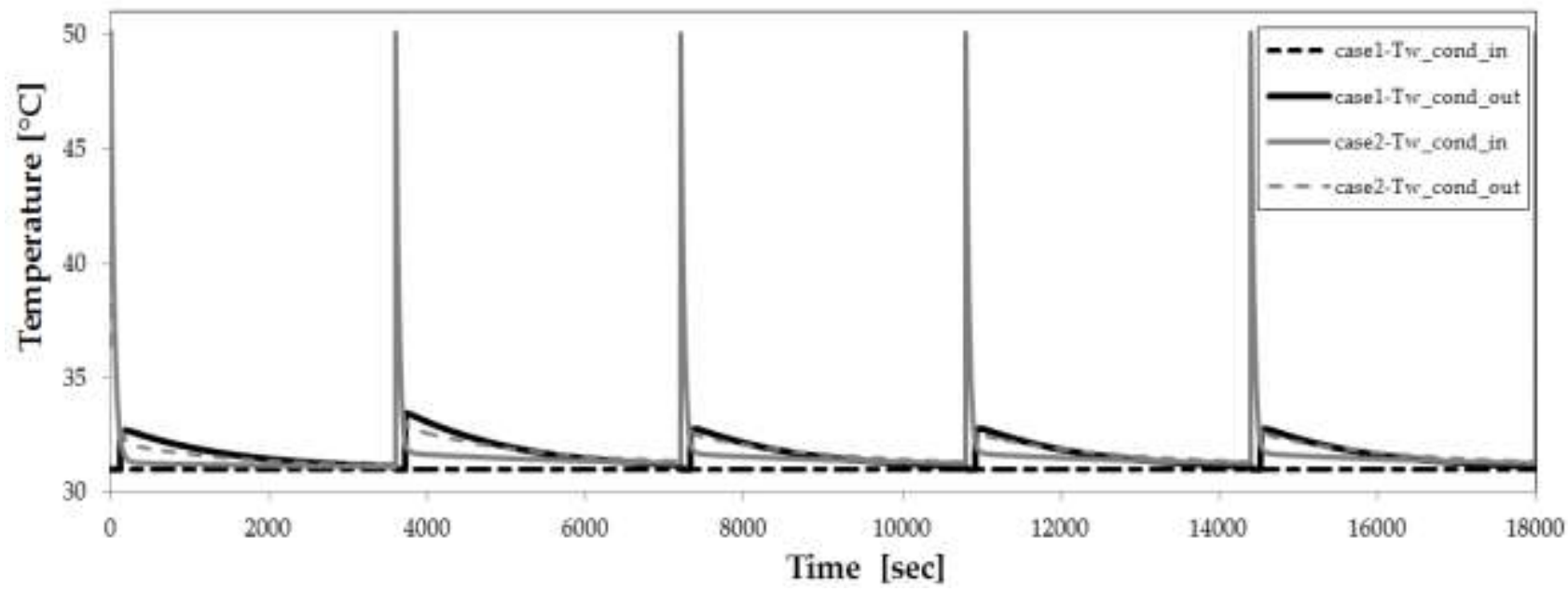

Fig. 13. 


\section{$\underline{\text { Figure List }}$}

Fig. 1a: Crystal structure of CPO-27(Ni), the adsorbed water molecules, 2,5 Dihydroxyterephthalic acid as the organic linker and Nickel nodes. $(\mathrm{H}, \mathrm{O}, \mathrm{C}, \mathrm{Ni}$ are in white, red, grey and violet respectively)

Fig. 1b: Experimental and simulated XRD patterns of CPO-27(Ni).

Fig. 1c: Particle size distribution analysis of $\mathrm{CPO}-27(\mathrm{Ni})$.

Fig. 2: Pore size distribution of CPO-27(Ni).

Fig. 3a: Water adsorption isotherms for CPO-27(Ni) and silica gel-RD at $25^{\circ} \mathrm{C}$.

Fig. 3b: Water adsorption isotherms of CPO-27(Ni) at different temperatures $\left(25^{\circ} \mathrm{C}, 35^{\circ} \mathrm{C}\right.$ and $\left.55^{\circ} \mathrm{C}\right)$.

Fig. 4: Performance cyclic analysis (adsorption/desorption cycles) of $\mathrm{CPO}-27(\mathrm{Ni})$ at $55^{\circ} \mathrm{C}$.

Fig. 5: Proposed isotherm model fitting of water adsorption on CPO-27(Ni).

Fig. 6: Fractional uptake of $\mathrm{CPO}-27(\mathrm{Ni})$ at $25^{\circ} \mathrm{C}(\mathrm{P} / \mathrm{Ps}=0.05 \& 0.1)$ and at $55^{\circ} \mathrm{C}(\mathrm{P} / \mathrm{Ps}=0.05 \& 0.1)$.

Fig. 7a: Arrangement of chiller component in Simulink simulation interface.

Fig. 7b: Validation of Transient Simulink Model.

Fig. 8: Energy distribution during cooling and storage mode $\left(\mathrm{T}_{\text {cooling }}=31^{\circ} \mathrm{C}, \mathrm{T}_{\text {reg }}=100^{\circ} \mathrm{C}, \mathrm{T}_{\text {chilled }}=14^{\circ} \mathrm{C}\right)$.

(a) Silica gel-RD (630 sec half cycle time).

(b) $\mathrm{CPO}-27(\mathrm{Ni})(630 \mathrm{sec}$ half cycle time).

(c) Silica gel-RD (3600 sec half cycle time).

(d) $\mathrm{CPO}-27(\mathrm{Ni})(3600 \mathrm{sec}$ half cycle time).

Fig. 9: Energy storage density of various adsorbents.

Fig. 10a: Heat recovery from adsorption bed in CPO-27(Ni) system at $\mathrm{T}_{\text {chilled }}=20^{\circ} \mathrm{C}($ Half cycle time $1 \mathrm{hr}$ ).

Fig. 10b: Heat recovery from condenser in CPO-27(Ni) system at $\mathrm{T}_{\text {chilled }}=20^{\circ} \mathrm{C}$ (Half cycle time $1 \mathrm{hr}$ ).

Fig. 10c: Effect of evaporation temperature on the performance of CPO-27(Ni) (Half cycle time $1 \mathrm{hr}$, $\mathrm{T}_{\text {cooling }}=31^{\circ} \mathrm{C}$ and $\mathrm{T}_{\text {reg }}=90^{\circ} \mathrm{C}$ )

Fig. 10d: Effect of evaporation temperature on the performance of CPO-27(Ni) and silica gel-RD (Half cycle time $1 \mathrm{hr}, \mathrm{T}_{\text {cooling }}=31^{\circ} \mathrm{C}$ and $\mathrm{T}_{\text {reg }}=90^{\circ} \mathrm{C}$ ).

Fig. 11: Effect of heat exchangers conductance on recovered condenser energy $\left(\mathrm{T}_{\text {chilled }}=20{ }^{\circ} \mathrm{C}, \mathrm{T}_{\mathrm{reg}}=90\right.$ ${ }^{\circ} \mathrm{C}, \mathrm{T}_{\text {cooling }}=31{ }^{\circ} \mathrm{C}$ and half cycle time $1 \mathrm{hr}$ )

Fig. 12: Different cooling water flow strategies.

Fig. 13: Inlet and outlet cooling water temperatures from condenser for both cooling water flow strategies. 


\section{Table List}

Table 1: Pore structure of CPO-Ni using Pelsorb facility.

Table 2: Cycle standard rating condition (Dimensions of the unit [43]).

Table 3: Energy storage density of different adsorbents in TES application.

Table 4: Energy distribution with different strategies $\left(\mathrm{T}_{\text {cooling }}=31^{\circ} \mathrm{C}, \mathrm{T}_{\text {reg }}=100^{\circ} \mathrm{C}\right.$ and $\left.\mathrm{T}_{\text {chilled }}=14^{\circ} \mathrm{C}\right)$. 
Table 1: pore structure of CPO-27(Ni)

\begin{tabular}{|c|c|c|}
\hline Surface area $\left(\mathrm{m}^{2} / \mathrm{g}\right)$ & $\begin{array}{c}\text { Total Pore volume } \\
\mathrm{cm}^{\mathbf{3}} / \mathrm{kg}\end{array}$ & $\begin{array}{c}\text { Pore mean diameter } \\
(\mathbf{n m})\end{array}$ \\
\hline 299 & 217 & 0.7 \\
\hline
\end{tabular}

Table 2: validation Cycle standard rating condition (Dimensions of the unit [43])

\begin{tabular}{|lcc|}
\hline Physical parameter & Value & Units \\
\hline Chilled water supply & 14 & ${ }^{\circ} \mathrm{C}$ \\
Hot regeneration water & 85 & ${ }^{\circ} \mathrm{C}$ \\
Cooling water & 31 & ${ }^{\circ} \mathrm{C}$ \\
Chilled water flow rate & $\mathrm{kg} / \mathrm{s}$ \\
Hot water flow rate & 0.7 & $\mathrm{~kg} / \mathrm{s}$ \\
Condenser cooling water flow rate & 1.3 & $\mathrm{~kg} / \mathrm{s}$ \\
Adsorption bed cooling water flow rate & 1.3 & $\mathrm{~kg} / \mathrm{s}$ \\
Half cycle time & 1.6 & $\mathrm{Sec}$ \\
Switching time & 420 & $\mathrm{Sec}$ \\
\hline
\end{tabular}

Table 3: Energy storage density of different adsorbents in TES application

\begin{tabular}{|l|c|c|c|}
\hline \multicolumn{1}{|c|}{ Material } & Ref. & $\begin{array}{c}\text { Charging temperature } \\
\left.\text { ( }{ }^{\mathbf{C}} \mathbf{C}\right)\end{array}$ & $\begin{array}{c}\text { Energy storage density } \\
\text { (Wh.kg-1) }\end{array}$ \\
\hline CPO-27(Ni) & Current study & 100 & 170.2 \\
\hline Silica gel-RD & Current study & 100 & 180.85 \\
\hline Zeolite-13X & {$[25]$} & 220 & 306.45 \\
\hline Zeolite-5A & {$[35]$} & 103 & 63.4 \\
\hline Zeolite-13X & {$[44]$} & 180 & 149 \\
\hline SWS-1L & {$[45]$} & 90 & 132 \\
\hline
\end{tabular}

Table 4: Energy distribution with different strategies $\left(\mathrm{Tcooling}^{\circ}=31^{\circ} \mathrm{C}, \mathrm{Treg}=100^{\circ} \mathrm{C}, \mathrm{Tchilled}=14^{\circ} \mathrm{C}, \mathrm{Half}\right.$ cycle time $=3600 \mathrm{sec}$ )

\begin{tabular}{|l|c|c|c|c|c|}
\hline & $\begin{array}{c}\text { Q_adsorber } \\
{[\mathbf{k W h r}]}\end{array}$ & $\begin{array}{c}\text { Q_condenser } \\
{[\mathbf{k W h r}]}\end{array}$ & $\begin{array}{c}\text { Condenser mass } \\
\text { flow [kg/s] }\end{array}$ & $\begin{array}{c}\text { Adsorber mass flow } \\
{[\mathbf{k g} / \mathbf{s}]}\end{array}$ & $\begin{array}{c}\text { Total energy recovered } \\
{[\mathbf{k W h r}]}\end{array}$ \\
\hline Concept 1 & 7.8296 & 3.5581 & 1.3 & 1.6 & 11.3877 \\
\hline Concept 2 & 7.8129 & 3.4376 & \multicolumn{2}{|c|}{$1.3+1.6$} & 11.2505 \\
\hline
\end{tabular}

